\title{
Manejo de drogas peligrosas y sus medidas de bioseguridad en el Sistema de Salud de Uruguay
}

\section{Management of dangerous drugs and their biosecurity} measures in the Uruguayan Health System

\section{Manejo de drogas perigosas e suas medidas de biossegurança no Sistema de Saúde Uruguaio}

\author{
doi http://dx.doi.org/10.35954/SM2019.38.2.3 \\ Elena Oliva (D) https://orcid.org/0000-0002-7427-3410 \\ Doctora en Enfermería. Especialista en Hemato-oncología. \\ Docente y coordinadora del postgrado en enfermería oncológica. \\ Facultad de Ciencias de la Salud. Universidad Católica del Uruguay.
}

\section{RESUMEN}

Objetivos: Identificar las medidas de bioseguridad adoptadas y utilizadas por el equipo de salud y conocer la percepción de riesgos y las dificultades de los mismos en el manejo de las drogas peligrosas en el Sistema de Salud de Uruguay. Método: Se realizó un estudio mixto con el personal de salud que maneja las drogas peligrosas en ocho instituciones de salud del área metropolitana de Montevideo, Uruguay. La fase cuantitativa se trató de un estudio observacional, exploratorio de corte transversal y la fase cualitativa utilizó la técnica de grupos focales con análisis de contenido. De 188 profesionales y técnicos de salud de las ocho instituciones de salud involucrados en el manejo de las drogas peligrosas, 145 participaron del estudio, entre ellos, 76 auxiliares de enfermería, 32 licenciados de enfermería, 27 auxiliares de servicio, 8 químicos farmacéuticos y 2 auxiliares de farmacia. Se destaca de los 145 participantes, 71 pertenecían a instituciones públicas y 74 a instituciones privadas. La recolección de los datos cuantitativos fue realizada mediante la técnica de observación estructurada y no participativa. Para conocer la percepción de los riesgos y las dificultades en el manejo de las drogas peligrosas según el personal de salud, se utilizó la técnica del grupo focal. Los datos fueron almacenados y analizados en el programa Microsoft Office Excel 2007. Se realizó un análisis descriptivo con frecuencia relativa y absoluta de las variables. Para los datos cualitativos se realizó análisis temático con base en categorías previamente elaboradas, o de modo inductivo a partir de todas las respuestas producidas en el grupo. Resultados: En las ocho instituciones de salud, publicas y privadas, el personal que recibe y almacena las drogas peligrosas es indistinto, licenciadas en enfermería, químicos farmacéuticos, auxiliares de enfermería y/o auxiliares de farmacia, según disponibilidad y no todo el personal que realiza esta tarea usa equipo de protección personal. Durante la preparación de las drogas peligrosas no todas las instituciones cuentan con el equipo de protección personal adecuado, solo el $12,5 \%$ de las Instituciones dispone de batas exclusivamente diseñadas para quimioterapia, $62,5 \%$ dispone de sobre túnicas impermeables y un $25 \%$ de impermeables, comunes y de tela. Ninguna de las ocho instituciones cuenta con guantes de quimioterapia. La preparación de las drogas peligrosas está a cargo en una institución de los químicos farmacéuticos y de las licenciadas en enfermería, en otra de las ocho a cargo de los auxiliares de farmacia y en las seis restantes a cargo de 
las licenciadas en enfermería y/o auxiliares de enfermería. La administración de las drogas peligrosas está a cargo de las licenciadas en enfermería y auxiliares de enfermería en el total de las instituciones participantes del estudio. Los químicos farmacéuticos en su totalidad cumplen con todas las actividades de los diferentes procesos. El proceso de análisis de contenido permitió la generación de tres categorías: 1. Dificultades en el manejo de las drogas peligrosas, 2. Percepción de Riesgos, 3. Logros obtenidos en el Manejo de las Drogas Peligrosas.

Por medio de los relatos se pudo identificar dificultades relacionadas a recursos humanos, materiales y de infraestructura, además de debilidades en el conocimiento, ausencia de protocolos, debilidades en las capacitaciones, la falta de apoyo institucional y ausencia de un marco regulatorio relacionado al manejo de las drogas peligrosas a nivel nacional. El personal que maneja las drogas peligrosas reconoce los riesgos y tiene la conciencia de que siempre están presentes. En los relatos, se verificó que los logros obtenidos caracterizados por la autoformación fueron más bien por esfuerzo personal. En cuanto a los recursos materiales y de infraestructura, el personal ha conquistado negociando con las instituciones a lo largo de los años. Conclusiones: A la luz de los objetivos planteados en este estudio, se concluye que no hay cumplimiento de las recomendaciones de los estándares internacionales. La necesidad de Políticas Públicas en el país, con un marco regulatorio que rija a todas las Instituciones de Salud, posibilitaría un cambio en la situación actual, disminuyendo los posibles riesgos a los que se expone el personal de salud.

PALABRAS ClAVE: Bioseguridad; Citostáticos /administración \& dosificación; Contención de Riesgos Biológicos = Bioseguridad; Educación en Enfermería lestadística \& datos numéricos; Exposición Profesional; Factores Biológicos lefectos de la radiación; Personal de Enfermería.

\section{ABSTRACT}

Objectives: To identify the biosecurity measures adopted and used by the health team and to know the perception of risks and the difficulties of the health team in the handling of dangerous drugs in the Uruguayan Health System. Methods: A mixed study was conducted with health personnel who handle dangerous drugs in eight health institutions in the metropolitan area of Montevideo, Uruguay. The quantitative phase was an observational, exploratory cross-sectional study and the qualitative phase used the focus group technique with content analysis. Of 188 health professionals and technicians from the eight health institutions involved in the management of dangerous drugs, 145 participated in the study, including 76 nursing assistants, 32 nursing graduates, 27 service assistants, 8 pharmaceutical chemists, and 2 pharmacy assistants. It should be noted that of the 145 participants, 71 belonged to public institutions and 74 to private institutions. Quantitative data collection was carried out using the structured, non-participatory observation technique. The focus group technique was used to determine the perception of risks and difficulties in handling dangerous drugs according to health personnel. The data were stored and analyzed in the Microsoft Office Excel 2007 program. A descriptive analysis was carried out with relative and absolute frequency of the variables. For the qualitative data, thematic analysis was conducted based on previously elaborated categories, or in an inductive way from all the responses produced in the group. Results: In the eight health institutions, public and private, the staff that receives and stores dangerous drugs is indistinct, licensed nurses, chemical pharmacists, nursing assistants and/or pharmacy assistants, according to availability, and not all the staff that performs this task uses personal protection equipment. During the preparation of dangerous drugs not all institutions have adequate personal protection equipment, only $12.5 \%$ of the institutions have gowns exclusively designed for chemotherapy, $62.5 \%$ have waterproof overalls 
and $25 \%$ have common and cloth waterproof overalls. None of the eight institutions have chemotherapy gloves. The preparation of dangerous drugs is carried out in one institution by pharmaceutical chemists and graduate nurses, in another of the eight by pharmacy assistants and in the remaining six by graduate nurses and/or nursing assistants. The administration of dangerous drugs is carried out by the graduate nurses and nursing assistants in all the institutions participating in the study. The pharmaceutical chemists as a whole comply with all the activities of the different processes. The technique of content analysis allowed the generation of three categories: 1. Difficulties in handling dangerous drugs, 2. Risk Perception, 3. Achievements in the Management of Dangerous Drugs.

Through the stories, difficulties related to human, material and infrastructure resources were identified, as well as weaknesses in knowledge, the absence of protocols, weaknesses in training, the lack of institutional support and the absence of a regulatory framework related to the management of dangerous drugs at the national level. Staff who handle dangerous drugs recognize the risks and are aware that they are always present. The stories verify that the achievements characterized by self-training were more of a personal effort. In terms of material resources and infrastructure, the staff has conquered by negotiating with the institutions over the years. Conclusions: In the light of the objectives set out, it can be deduced that there is no compliance with the recommendations of international standards. The need for public policies in the country, with a regulatory framework that governs all health institutions, would make it possible to change the current situation that was observed, reducing the possible risks to which health personnel are exposed.

KEY WORDS: Biosecurity; Cytostatic Agents /administration \& dosage; Containment of Biohazards; Education, Nursing /statistics \& numerical data; Ocupational Exposure: Biological Factors /radiation effects; Nursing staff.

\section{RESUMO}

Objetivos: Identificar as medidas de biossegurança adoptadas e utilizadas pela equipa de saúde e conhecer a percepção dos riscos e as dificuldades da equipa de saúde na manipulação de drogas perigosas no Sistema de Saúde Uruguaio. Métodos: Foi realizado um estudo misto com pessoal de saúde que lida com drogas perigosas em oito instituições de saúde na área metropolitana de Montevideo, Uruguai. A fase quantitativa foi um estudo transversal observacional e exploratório e a fase qualitativa utilizou a técnica de grupo focal com análise de conteúdo. De188 profissionais e técnicos de saúde das oito instituições de saúde envolvidas na gestão de medicamentos perigosos, 145 participaram no estudo, incluindo 76 assistentes de enfermagem, 32 licenciados em enfermagem, 27 assistentes de serviço, 8 químicos farmacêuticos, e 2 assistentes de farmácia. Dos 145 participantes, 71 pertenciam a instituições públicas e 74 a instituições privadas. A recolha de dados quantitativos foi realizada utilizando a técnica de observação estruturada e não participativa. A técnica do grupo focal foi utilizada para determinar a percepção dos riscos e dificuldades no manuseamento de drogas perigosas de acordo com o pessoal de saúde. Os dados foram armazenados e analisados no programa Microsoft Office Excel 2007. Foi realizada uma análise descritiva com frequência relativa e absoluta das variáveis. Para os dados qualitativos, a análise temática foi realizada com base em categorias previamente elaboradas, ou de forma indutiva a partir de todas as respostas produzidas no grupo. Resultados: As oito instituições de saúde, públicas e privadas, o pessoal que recebe e armazena os medicamentos perigosos é indistinto, enfermeiros licenciados, farmacêuticos químicos, assistentes de enfermagem e/ou auxiliares de farmácia, de acordo com a disponibilidade e nem todo o pessoal que executa esta tarefa utiliza equipamento de protecção pessoal. 
Durante a preparação de medicamentos perigosos nem todas as instituições possuem equipamento de protecção pessoal adequado, apenas $12,5 \%$ das instituições possuem vestidos exclusivamente concebidos para quimioterapia, $62,5 \%$ possuem macacões impermeáveis e $25 \%$ possuem macacões comuns e de pano impermeável. Nenhuma das oito instituições dispõe de luvas de quimioterapia. A preparação de medicamentos perigosos é efectuada numa instituição por químicos farmacêuticos e enfermeiros graduados, noutra das oito por auxiliares de farmácia e nas seis restantes por enfermeiros graduados e/ou auxiliares de enfermagem. A administração de drogas perigosas é realizada pelos enfermeiros e assistentes de enfermagem diplomados em todas as instituições que participam no estudo. Os químicos farmacêuticos cumprem na sua totalidade todas as actividades dos diferentes processos. A técnica de análise de conteúdo permitiu a geração de três categorias: 1. dificuldades no manuseamento de drogas perigosas, 2. Percepção de Risco, 3. Realizações na Gestão de Drogas Perigosas.

Através das histórias, foram identificadas dificuldades relacionadas com recursos humanos, materiais e infra-estruturais, bem como fraquezas no conhecimento, a ausência de protocolos, fraquezas na formação, a falta de apoio institucional e a ausência de um quadro regulamentar relacionado com a gestão de drogas perigosas a nível nacional. Os funcionários que lidam com drogas perigosas reconhecem os riscos e estão conscientes de que eles estão sempre presentes. As histórias verificam que as realizações caracterizadas pela auto-formação foram mais um esforço pessoal. Em termos de recursos materiais e infra-estruturas, o pessoal conquistou ao longo dos anos, negociando com as instituições. Conclusões: luz dos objetivos estabelecidos, pode deduzir-se que não há conformidade com as recomendações das normas internacionais. A necessidade de políticas públicas no país, com um quadro regulamentar que regule todas as instituições de saúde, permitiria alterar a situação actual que foi observada, reduzindo os possíveis riscos a que o pessoal de saúde está exposto.

PALAVRAS CHAVE: Biosegurança; Citostáticos /administração \& dosagem; Contenção de Riscos Biológicos; Educação em Enfermagem lestatística \& dados numéricos; Exposiçao Ocupacional; Fatores Biológicos /efeitos da radiação; Recursos Humanos de Enfermagem.

\section{INTRODUCCIÓN}

Cuando se habla de drogas peligrosas, se hace referencia a un amplio grupo de medicamentos con mecanismos de acción muy diversos, pero con la característica común de interrumpir el ciclo celular en alguna de sus fases. Esta propiedad permite utilizarlos en el tratamiento de enfermedades neoplásicas como terapia única o en combinación con radioterapia y/o cirugía. La constante evolución de los protocolos, la utilización de nuevas técnicas y la aparición de nuevos medicamentos han permitido incrementar el número de pacientes tratables y las expectativas de éxito. A pesar de ello, no se debe olvidar que se trata de fármacos muy activos, con elevada toxicidad potencial. Su uso se inicia en 1943 tras la observación de aplasias medulares en militares expuestos a gas mostaza durante la Segunda Guerra Mundial, lo que propicia la utilización de mostaza nitrogenada en el tratamiento de la enfermedad de Hodgkin. El aumento en todo el mundo occidental de los casos de cáncer, que son tratados en su gran mayoría con quimioterapia antineoplásica, sumado a la diversificación de usos que han sufrido los agentes citostáticos en estos últimos años y el resultado del avance en los conocimientos médicos, implica que estos medicamentos sean cada vez más usados en terapéutica asistencial. Este hecho conlleva a un incremento paralelo del riesgo para la salud de los trabajadores/as que los manipulan, conocido ya desde los años 70 (1). 
En los años 70 se establece la conexión entre varias drogas citotóxicas y el desarrollo de leucemia secundaria en pacientes que habían recibido tratamiento oncológico. Frente a esta evidencia, expertos indican que el riesgo podía extenderse al personal que preparaba las drogas (2).

A los riesgos ya conocidos de irritación de piel y mucosas por aplicación directa, se ha evidenciado la posibilidad de riesgo para la salud en el personal que los manipula, tras exposición crónica y en pequeñas cantidades. La exposición contínua y prolongada a pequeñas dosis puede tener efectos mutagénicos, embriotóxicos, teratogénicos y carcinogénicos sobre el personal manipulador (3), además de la presencia de residuos contaminados en las superficies laborales en las farmacias y en las áreas de administración (4).

Un estudio realizado en seis centros oncológicos de los Estados Unidos y Canadá, reportó contaminación en las muestras de $75 \%$ de las superficies laborales en las farmacias y $65 \%$ en las muestras de las áreas de administración, y refiere que los controles y la práctica en el trabajo no impiden la liberación de drogas peligrosas (5).

En 1999, Burgaz determinó la excreción urinaria de ciclofosfamida y la frecuencia de micro núcleos en linfocitos periféricos y en células exfoliadas del epitelio bucal, de 26 enfermeras que manipulaban citostáticos y 14 controles. Se obtuvo una tasa de excreción del fármaco en el rango de 0,02 $-9,14 \mathrm{mg} / 24 \mathrm{~h}$ en el grupo de enfermeras expuestas y valores medios de la frecuencia de micronúcleos en linfocitos periféricos de las enfermeras expuestas y de los controles de 0,61 y 0,28 respectivamente. El valor medio de la frecuencia de micronúcleos de células del epitelio bucal de las enfermeras expuestas fue de 0,16 y para el control de 0,08 (6). Weidner, en el año 2000, realizó un estudio de seguimiento durante cuatro años del daño genético en linfocitos de 10 farmacéuticos y enfermeras que manipulaban antineoplásicos y de un grupo control de 10 individuos no expuestos. Los resultados mostraron superioridad de los valores de las frecuencias de micro núcleos de los linfocitos en el grupo expuesto respecto al control (7). En un estudio similar, Undeg̃er estudia la influencia de las características de trabajo y obtiene como resultado una diferencia en el grupo de las enfermeras expuestas a estas drogas, entre las que utilizaban correctamente los medios de protección y las que no la hacían (8).

También ha sido estudiada la relación entre la exposición ocupacional a citostáticos y los riesgos reproductivos que esta entraña. Un estudio conducido por Hemminki, obtuvo correlación estadísticamente significante entre el nacimiento de niños con malformaciones y la exposición de sus madres a antineoplásicos, en la preparación y administración más de una vez por semana durante el primer trimestre de embarazo con pocos o ningún medio de protección (9). Mientras que Selevan, examinó solo la incidencia de pérdidas fetales y demostró una asociación significativa entre estas y la exposición ocupacional de las madres a antineoplásicos durante el primer trimestre del embarazo (10). Igualmente se ha observado que existe una asociación entre las disfunciones menstruales y el manejo de estas drogas (11).

Existen evidencias que a dosis terapéuticas estas drogas muestran supresión de la función testicular y de la espermatogénesis. Aunque la relación de esta propiedad y la exposición ocupacional no han sido estudiadas, esta complicación potencial debe ser considerada $(12,13)$.

En 1992, Sessink publica nuevos datos relacionados con la exposición de drogas peligrosas. Este fue el primero de los 14 estudios que encontraron residuos de drogas peligrosas en las superficies de trabajo de las farmacias y las áreas de administración de fármacos (14).

La preparación, administración y eliminación de las drogas peligrosas conlleva la exposición de diversos profesionales de la salud, sin embargo, la evidencia refiere que el profesional de enfermería presenta el mayor riesgo de exposición, en particular durante la preparación del fármaco (15-17). 
Para prevenir los posibles efectos secundarios de una manipulación inadecuada se debe aplicar una sistemática de trabajo apropiada y adoptar determinadas medidas de actuación frente a cualquier situación en la que estén implicados los medicamentos peligrosos (18).

Diferentes organismos de reconocimiento internacional, encargados de proteger la salud y la seguridad de los trabajadores, han publicado recomendaciones de manipulación de estos fármacos (19-21). En Uruguay no existen políticas públicas relacionadas a modelos de bioseguridad que contemplen normativas y recomendaciones estipuladas para que los trabajadores de la salud cuenten con las precauciones necesarias en el manejo de las drogas peligrosas. En el Sistema de Salud de Uruguay, cada institución tiene políticas de trabajo diferentes.

Es importante trabajar sobre este tema por la magnitud del riesgo al que se exponen todos los trabajadores de salud, no solo los que preparan o administran dichas drogas, sino también los que las trasladan, almacenan, limpian y desechan los residuos.

La exploración de la realidad local del Sistema de Salud de Uruguay en el manejo de las drogas peligrosas, posibilitará el conocimiento de los riesgos a que están expuestos los trabajadores de la salud que preparan, administran, transportan estas drogas, desechan residuos de los mismos y que enfrentan diariamente riesgos para su propia salud. Investigar la realidad del Sistema de Salud de Uruguay y lo que dice respecto al manejo de las drogas peligrosas, en especial a los citostáticos, forjará una línea de base para la propuesta de medidas de bioseguridad basadas en los mejores estándares internacionales, que respondan a la realidad local y generará conocimientos relacionados a la práctica de enfermería que posibilitarán nuevos enfoques de cuidados más seguros a las personas y al propio equipo de salud.

\section{OBJETIVOS}

Conocer la percepción de riesgos y las dificultades, así como medidas de bioseguridad adoptadas y utilizadas por el equipo de salud en el manejo de las drogas peligrosas en el Sistema de Salud de Uruguay.

Caracterizar los recursos humanos, materiales y estructurales involucrados en el manejo de las drogas peligrosas, a partir de los discursos del equipo de salud, la percepción de los riesgos y las dificultades, analizar el manejo de las mismas. Identificar los procesos existentes en el manejo de las drogas peligrosas en cuanto a la recepción, almacenamiento, preparación, administración y desecho de los residuos.

\section{MARCO TEÓRICO}

\section{Las drogas peligrosas los riesgos y los daños}

Las drogas peligrosas son clasificadas de acuerdo a los daños que pueden causar a las personas. Son consideradas genotóxicas cuando provocan un cambio o mutación en el material genético, carcinotóxicas cuando causan cáncer en humanos o animales y, teratogénicas cuando producen malformación fetal. Se ha evidenciado además problemas de fertilidad en hombres y mujeres con exposición laboral a estas drogas. Dentro de estas se encuentran los agentes antineoplásicos o citostáticos, los agentes biológicos, los agentes antivirales y los inmunosupresores (14-22).

El personal del sector salud, y más aún el personal de enfermería que está en contacto directo, ya sea durante la preparación y/o administración, que trabaja con drogas peligrosas o cerca de las mismas, puede quedar expuesto a estos agentes presentes en el aire, las superficies de trabajo, la ropa, el equipo médico y los fluidos corporales (orina, deposiciones, vómitos) entre otros $(16,18)$. Un estudio realizado en 36 hospitales canadienses, encontró contaminación ambiental de las 
drogas ciclofosfamida, ifosfamida y metotrexato en los servicios de farmacia y hospitalización de pacientes y concluyó que no existe un límite de exposición a las drogas antineoplásicas (23).

Trabajadores que pueden sufrir exposición laboral incluyen el personal que distribuye o transporta las drogas, que las recibe y almacena, los farmacéuticos, técnicos, enfermeras/os y personal que está en el ambiente. Las fuentes de exposición son variadas; por inhalación de aerosoles y microgotas que se desprenden durante la preparación de las soluciones, por contacto directo, por la penetración del medicamento a través de la piel o de las mucosas, por vía oral y parenteral. El traslado de las drogas de contenedor a contenedor, el conectar y desconectar las tubuladuras a los sachets, el conectar y desconectar jeringas a las vías, el conectar y desconectar el set de bomba a la vía del paciente y a la manipulación de fluidos corporales de los pacientes, también son acciones con un gran riesgo de exposición $(14,22)$.

Considerando los daños, el personal de salud expuesto a las drogas peligrosas, en especial a los citostáticos, ha reportado eventos agudos como irritación de la piel, dolor de garganta, tos, mareos, dolor de cabeza, reacciones alérgicas, alteraciones en el ciclo menstrual, diarrea, náuseas y vómito, entre otros $(4,11)$.

Respecto a los daños a largo plazo, estudios han demostrado daño hepático en el caso de tres enfermeras de una unidad de oncología que trabajaban administrando medicamentos citotóxicos durante varios años (23), niveles altos de sustancias mutagénicas en muestras de orina, de enfermeras que preparaban y administraban citostáticos, en comparación con enfermeras que no estaban expuestas $(14,22)$ y aumento de interrupciones de embarazos, malformaciones congénitas, bajo peso al nacer e infertilidad $(9,10)$.

En la evidencia científica respecto del manejo de las drogas peligrosas, prevalecen los estudios relacionados a los agentes citostáticos. Asimis- mo, se observa en la literatura un predominio de estudios relacionados a los riesgos a que están expuestos los enfermeros, principalmente en la preparación y administración de estos agentes, y relativos al conocimiento y cumplimiento de los estándares de seguridad en el manejo de estas drogas (15-17,22-26).

Un estudio realizado con 165 enfermeras de centros oncológicos americanos, analizó factores que promueven la utilización correcta de las precauciones en el manejo de los citostáticos. Encontró que el conocimiento de la exposición, la autoeficacia para el uso de equipo de protección personal y el riesgo percibido de daño por exposición, eran altos. El uso total de precaución fue baja. Además, el estudio comprobó que menos barreras, mejor clima de seguridad laboral y un menor número de pacientes por día, eran predictores independientes de mayor uso de precaución necesaria (16). Los profesionales de enfermería reconocen los riesgos al que están expuestos, sin embargo, la literatura es explicita en la no adopción de las normas de manejo adecuado de las drogas por estos profesionales $(24,27,28)$, lo que es incoherente con la percepción expresada por los mismos (27).

\section{Bioseguridad}

La bioseguridad esta entendida como un conjunto de normas y procedimientos considerados seguros y adecuados para la manutención de la salud de los trabajadores en la realización de actividades de riesgos. En el contexto de la salud, la bioseguridad está íntimamente relacionada con la seguridad de los cuidados brindados a las personas y a las buenas prácticas. La intersección de las buenas prácticas, de la seguridad del trabajador y de las personas, además de la calidad de la asistencia, depende no solo de los factores relacionados a los procesos y estructuras sino también a los factores sociales y personales (29). La literatura refiere que el gran problema de la bioseguridad no está en las tecnologías disponibles para minimizar los riesgos, sino en los com- 
portamientos y en las prácticas cotidianas de los profesionales. La evidencia específicamente relacionada a los comportamientos y percepciones del personal que maneja drogas peligrosas, en especial los citostáticos, es incipiente, sin embargo, estudios demuestran la bioseguridad desde la perspectiva de los profesionales en otras situaciones de riesgo en el contexto de la salud $(30,31)$. Un estudio brasileño que tuvo por objetivo investigar los saberes y prácticas del equipo de enfermería respecto a la bioseguridad en unidades de cuidados intensivos, demostró el cumplimiento parcial de las normas de bioseguridad de las instituciones y la deficiencia de reconocimiento y debates sobre el tema en el espacio de la educación continua de los profesionales (31). Otro estudio, sobre las creencias de los trabajadores de la salud frente a accidentes con fluidos biológicos, refiere la incorporación de comportamientos preventivos a los riesgos posteriores al accidente, además del escaso investimento de las instituciones de salud en la seguridad de los trabajadores (32).

En España, un estudio con 177 profesionales sanitarios identificó la percepción de riesgo respecto a la gestión de los residuos sanitarios. El nivel medio de percepción de riesgo de los técnicos de enfermería, los enfermeros, los médicos y los técnicos de laboratorio, en una escala de 1 a 5 fue de $3.71,3.75,3.83$ y 4.03 respectivamente, siendo considerada alta, aunque solo un $44,8 \%$ consideró que los residuos sanitarios son tóxicos y peligrosos (33).

En consideración a los citostáticos, los profesionales de enfermería son los que más se exponen a los riesgos durante los cuidados brindados a los pacientes. La literatura es enfática en el sentido de que los enfermeros aunque reconocen los riesgos a los que se exponen, muchos de ellos no siguen las normas establecidas para la realización de un cuidado seguro para sí y para los pacientes $(24,27,28,34)$.

\section{Mejores estándares para el manejo de las drogas peligrosas}

La organización The Occupational Safety and Health Administration (OSHA) (18), que a principios de la década de los 80 se interesó por el riesgo ocupacional durante la manipulación de citostáticos, implementó un programa de manipulación segura de agentes quimioterápicos, donde se describía el equipamiento, la protección y las técnicas de trabajo que debían adoptar los trabajadores para evitar la exposición a estos fármacos. Así lo hicieron también otras organizaciones internacionales como: The American Society of Hospital Pharmacists (ASHP) (19), The National Institute for Occupational Safety and Health (NIOSH) (20) y The Institute for Applied Healthcare Sciences (IFAHS) (21).

Antes de la década de los 80 , la práctica habitual de manipulación de citostáticos incluía la utilización de Cabinas de Flujo Laminar Horizontal (CFLH), además de escasa utilización de equipos de protección por parte del personal manipulador, con el consiguiente riesgo de exposición. A partir de 1980 empezaron a aparecer estudios en los que se ponía de manifiesto los peligros potenciales asociados a la preparación y administración de estos medicamentos y la escasa seguridad que ofrecían las prácticas que se estaban utilizando hasta ese momento. Una de las primeras intervenciones que se emprendieron como medida de reducción del riesgo fue el cambio de CFLH por Cabinas de Seguridad Biológica (CSB). A partir de ese momento, diferentes organizaciones profesionales y agencias gubernamentales publicaron una serie de recomendaciones acerca de la manipulación segura de citostáticos (22).

\section{Cabinas de Seguridad Biológica}

El área de preparación de citostáticos debe estar ubicada en una zona restringida, de poco acceso, solo para personal autorizado. La centralización de la preparación de estos productos garantiza 
una mayor seguridad para el trabajador y el medio ambiente, reduciendo en gran medida el riesgo de exposición. Debe estar dividida en dos zonas, una semilimpia (zona de acceso restringido para el almacenamiento de sueros y material de preparación) y la zona limpia donde se encuentra ubicada la CSB (18-21).

Las normas de trabajo dentro de la Cabina de Seguridad Biológica aseguran una correcta protección. La ASHP y la OSHA recomiendan que la CSB esté en funcionamiento las 24 horas del día los 7 días de la semana. Si esto no fuese posible, tanto al conectarla como al desconectarla debe estar colocada la tapa frontal $(18,21)$. En caso de que se desconecte la CSB, ésta debe estar en funcionamiento como mínimo 20 minutos antes de iniciar la sesión de trabajo, con el fin de permitir el arrastre de las partículas en suspensión. En el interior de la CSB sólo se debe introducir el material imprescindible para preparar un tratamiento, dicho material se debe distribuir de manera que no obstaculice el flujo de aire. También habrá dentro de la CSB un contenedor para desechar agujas. La manipulación de los medicamentos se debe realizar en la parte central de la CSB a una distancia de 20 centímetros o más, del extremo exterior de ella. El material y objetos necesarios para la preparación, deben ser colocados en los laterales de forma que queden alejados de la parte central donde se realiza la manipulación de los fármacos y así evitar alteraciones del flujo. No se deben introducir papeles, cartones u otros materiales que desprendan partículas de polvo en su interior. La entrada y salida de los brazos se debe hacer en dirección paralela a la superficie de trabajo, evitando movimientos bruscos en el interior de la CSB a fin de mantener la integridad del flujo. La superficie de trabajo se cubrirá con una talla estéril, con la cara absorbente hacia arriba y la cara plastificada hacia abajo, con la finalidad de recoger cualquier salpicadura o derrame que se produzca. La talla se cambiará después de cada sesión de trabajo o cuando se produzca un derrame. El tiempo de trabajo continuado en la CSB no debería superar las dos horas, de forma que, por cada dos horas de trabajo continuado, se debería descansar 15 minutos. Es necesario que una empresa especializada realice controles de mantenimiento de la CSB de manera que se pueda verificar que se cumplen las especificaciones del fabricante (18-21).

\section{Normas para una correcta manipulación}

Entre las medidas preventivas que debe adoptar el personal manipulador para protegerse a sí mismo y el ambiente de posibles exposiciones durante la preparación de citostáticos, destacan las siguientes:

- No utilizar maquillaje facial, laca de uñas, laca o gomina en el pelo. Todos estos productos podrían aumentar la exposición al citostático en caso de contaminación.

- No comer ni beber dentro de la unidad de elaboración y manipulación.

- No almacenar comida ni bebida en el área de trabajo.

- No masticar goma de mascar.

- No fumar.

- No llevar relojes, anillos, pulseras u otros objetos que puedan romper los guantes durante la manipulación.

Si se produce un corte de luz o se detecta alguna anomalía en la CSB, colocar inmediatamente la tapa. A continuación, comunicar la incidencia al responsable de la unidad de citostáticos con el fin de tomar las medidas de corrección adecuadas, también se debería llevar un registro de todas las incidencias que se produzcan (18-21).

El uso adecuado de equipos de protección individual (EPI) es una de las mejores formas de prevenir la exposición ocupacional de los trabajadores frente a productos peligrosos. La prevención su- 
pone un punto clave en todos los pasos del proceso. La indumentaria necesaria está compuesta por bata, guantes, gorro, mascarilla, gafas y zapatones (18-21).

\section{Procesos de limpieza}

Dentro de los procesos de limpieza de la CSB se pueden distinguir dos tipos de mantenimiento, la limpieza diaria de la CSB que se debe realizar antes de iniciar cada sesión de trabajo y al finalizar, y una limpieza más profunda de forma periódica según el protocolo establecido en cada centro. Como mínimo, antes de iniciar el trabajo y al finalizar, se realizará diariamente una desinfección con alcohol de $70^{\circ}$; además, al finalizar la sesión y previo al alcohol se limpiará la superficie de la cabina con una solución de jabón alcalino. Se recomienda el uso de detergente ya que no existe un único método aceptado de descontaminación química para todos los citostáticos. Los limpiadores basados en sales de amonio cuaternario deberían evitarse debido a la posibilidad de creación de vapores en el aire recirculado. Todo el material utilizado en la limpieza se considera residuo citostático y por tanto se debe depositar en los contenedores específicos y homologados para estos fármacos (18-21).

\section{Actuación en caso de exposición o derrame}

Es importante disponer de un procedimiento de actuación en caso de exposición o derrame. El personal que trabaja en la unidad debe conocer el procedimiento y tener fácil acceso al material necesario para poder actuar de manera rápida y eficaz. Siempre que se produzca una exposición aguda o derrame, debe comunicarse al farmacéutico responsable y posteriormente al médico de vigilancia de la salud con el fin de que lo tenga en consideración y lo añada al historial médico de la persona afectada. Es importante disponer de un kit de derrame ubicado en las diferentes unidades donde se administren citostáticos, así como en farmacia. El kit debe ser fácilmente localizable y todo el personal que manipula citostáticos debe estar informado de su ubicación. Antes de proceder a recoger el derrame, si el fármaco ha entrado en contacto con la persona, se debe proceder de acuerdo a las normas de exposición accidental descritas anteriormente (18-21).

\section{Eliminación de residuos y tratamiento de excretas}

Los residuos citotóxicos se encuentran dentro de los residuos de riesgo o específicos, que son aquellos que por sus características y grado de contaminación química o biológica requieren un tratamiento específico y diferenciado de los residuos "urbanos" tanto fuera como dentro del centro. Se considera residuo citotóxico tanto los restos de medicamentos citostáticos como todo el material que ha estado en contacto con ellos. Proceden principalmente de restos de medicamentos citotóxicos generados en la preparación y administración; material cortante y/o punzante utilizado en la preparación y administración de éstos, material sanitario de un solo uso que ha estado en contacto con los medicamentos y que contiene trazas de sustancias citotóxicas, material de protección contaminado de los manipuladores, material utilizado para la limpieza de la zona de preparación y para el tratamiento de derrames $(18,21)$. Los residuos citotóxicos requieren la adopción de medidas de prevención en su recogida, almacenamiento, transporte y tratamiento, tanto dentro como fuera del recinto sanitario, dado que pueden generar un riesgo para la salud laboral y pública. La correcta separación en su origen permitirá reducir los riesgos laborales y ambientales ocasionados por una gestión incorrecta y evitar que estos residuos reciban un tratamiento inadecuado fuera del recinto. Las características técnicas requeridas para los contenedores son las siguientes: rigidez, estanqueidad total, opacidad, impermeabilidad y resistencia a la humedad, fácilmente manipulables, con resistencia a la rotura, 
asepsia total en su exterior, ausencia total en su exterior de elementos punzantes o cortantes, de un volumen no superior a 60-70 litros, de un solo uso, de materiales que permitan su incineración completa sin que generen emisiones tóxicas por combustión, resistentes a agentes químicos y a materiales perforantes. El transporte de estos residuos dentro de los centros es una operación que se debe realizar atendiendo a criterios de seguridad, inocuidad, asepsia, agilidad y rapidez. En general se recomienda que los contenedores no sean arrastrados, que se asegure el cierre completo y que el sistema de transporte que se utilice tenga un diseño adecuado que impida la caída de los contenedores y que permita ser desinfectado y lavado periódicamente. Los residuos citotóxicos pueden ser eliminados mediante incineración. La incineración se realiza en hornos especiales preparados para tal finalidad que garanticen una temperatura de combustión entre $1.000{ }^{\circ} \mathrm{C}$ y $1.200{ }^{\circ} \mathrm{C}$. Las excretas de los pacientes tratados con citostáticos deben ser consideradas material contaminante dado que pueden contener restos del medicamento o de sus metabolitos y, por tanto, deben recibir un tratamiento especial. Las excretas se deben considerar peligrosas al menos 48 horas después de finalizar el tratamiento, aunque este periodo puede ser variable dependiendo del fármaco. El procedimiento idóneo de eliminación debería de ser el mismo que para el resto de los residuos citotóxicos, pero cuando esto no sea posible se deberán diluir con abundante agua y ser eliminados por el desagüe. Siempre será necesario que el personal sanitario adopte medidas de protección en su eliminación (guantes y bata) para evitar la contaminación. Cuando éstas sean utilizadas para la realización de pruebas analíticas, la recogida, almacenamiento y manipulación se deberá realizar con especial protección y deberán estar correctamente identificados (18-21). La ropa de cama que ha estado en contacto con el paciente y sus excretas también ha de ser consi- derada material contaminado y, por tanto, deberá recibir un tratamiento diferente al convencional. Si el volumen es escaso se recomienda la utilización de material de un solo uso, pero cuando el volumen es importante se recomienda recogerla en bolsas lavables y transportarlas hasta la lavandería, contenidas en otras bolsas impermeables debidamente identificadas. Una vez en la lavandería, será necesario efectuar un prelavado antes de ser sometidas al ciclo de lavado convencional (8).

\section{Administración de citostáticos}

Está habitualmente a cargo del personal de enfermería, aunque en determinadas vías de administración pueden ser otros profesionales quienes administren la medicación, como es el caso de la vía oral, cuando se dispensa en el servicio de farmacia o en tratamientos intratecales, que los administra un médico. El personal de enfermería que administra este tipo de tratamientos debe poseer un perfil muy concreto, debe ser experto, tener conocimientos muy amplios sobre los tratamientos con los citostáticos y los diferentes protocolos de administración, sobre los efectos secundarios y su manejo, las diferentes vías de administración y las precauciones en la administración (18-21). Con la aparición de nuevos agentes quimioterápicos, los regímenes terapéuticos han cambiado, pero no dejan de ser tratamientos muy agresivos y con efectos secundarios importantes, que inciden en la calidad de vida de los pacientes, por lo que la educación sanitaria del paciente/familia sobre su enfermedad, los accesos vasculares y el manejo de los efectos secundarios una vez en el domicilio, debe formar parte de la atención que se ofrece al paciente en la fase de administración del tratamiento (8).

Los pacientes pueden recibir los tratamientos quimioterápicos mediante ingreso hospitalario o de manera ambulatoria en los hospitales de día, lo que decide el ingreso es el tipo de protocolo de tratamiento, el estado del paciente u otros criterios (14). 
La tendencia en la administración de la quimioterapia es realizar este proceso de forma ambulatoria debido a (8):

- Cambios en los protocolos de tratamiento y los mismos tratamientos.

- La posibilidad de la infusión continúa mediante una vía central y la posibilidad de escoger entre diferentes sistemas de administración.

- Cambios en la población que recibe tratamiento: el aumento de la incidencia del cáncer (algunos tipos de cáncer se caracterizan por aparecer en pacientes cada vez más jóvenes), el aumento de la incidencia de cáncer en otro sexo (por ejemplo, el cáncer de pulmón en el sexo femenino), el envejecimiento de la población, etc. Lo que supone un tipo de población muy concreta, pacientes en edad de mantener una actividad laboral y con cargas familiares tanto ascendentes como descendentes por un lado y por el otro, personas de edad avanzada que podrían ser independientes y que precisarán más atención.

- Cambios en la estructura social y familiar.

\section{Sistema de Salud de Uruguay}

El Sistema Nacional Integrado de Salud (SNIS) está compuesto por un sector público y un sector privado. El principal prestador de servicios públicos es la Administración de Servicios de Salud del Estado (ASSE), que cuenta con una red de establecimientos de cobertura nacional a las personas de escasos recursos sin cobertura de la seguridad social (35).

Las empresas o entes públicos (energía eléctrica, petróleo, agua, bancos) son parte del sector público de salud, por lo tanto, el cuidado y promoción de la salud de sus funcionarios corresponde al SNIS. En el interior del país, corresponde a las intendencias municipales ofrecer servicios de atención primaria a la población de menores recursos. Las intervenciones de alta complejidad de alto costo se llevan a cabo en los Institutos de
Medicina Altamente Especializada (IMAE) que son hospitales o clínicas especializadas, que pueden ser de origen público o privado. La prestación de servicios privada la dominan las Instituciones de Asistencia Médica Colectiva (IAMC), que son asociaciones de profesionales privadas sin fines de lucro que ofrecen atención integral a $56 \%$ de los uruguayos, los beneficiarios de la seguridad social. Estas instituciones también actúan como un seguro voluntario de la población con capacidad de pago. Los principales beneficiarios de SNIS son los trabajadores en relación de dependencia públicos y privados, los hijos de estos últimos menores de 18 años o mayores de esa edad con discapacidad, incluyendo a los del cónyuge o concubino y los jubilados. Son también beneficiarios los trabajadores del sector informal de la economía, los desempleados y los ciudadanos uruguayos que están fuera del mercado de trabajo y sus familias (35).

\section{MÉTODO}

\section{Tipo de estudio y diseño}

Se realizó un estudio mixto con el personal de salud que maneja las drogas peligrosas en ocho instituciones de salud (cuatro públicas y cuatro privadas) del área metropolitana de Montevideo, Uruguay. La fase cuantitativa se trató de un estudio observacional, exploratorio de corte transversal y la fase cualitativa se trató de un estudio cualitativo descriptivo que utilizó la técnica de grupo focal y análisis de contenido.

El universo estuvo conformado por un total de 188 profesionales y técnicos de salud, entre ellos 40 licenciadas en enfermería, 94 auxiliares de enfermería, 14 químicos farmacéuticos, 2 auxiliares de farmacia y 38 auxiliares de servicio, con experiencia mínima de seis meses en el servicio, relacionados con el manejo de las drogas peligrosas, ya sea en sitios que se preparan las drogas, internación y/u hospitales de día.

El Universo estuvo distribuido de acuerdo a cada 
institución de la siguiente forma:

\section{Institución privada II}

\section{Institución pública I}

- Licenciadas en enfermería:

10 asistenciales y 2 gestoras

- Auxiliares de enfermería: 31

- Auxiliares de servicio: 10

- Químicos farmacéuticos: 0

- Auxiliares de farmacia: 0

\section{Institución pública II}

- Licenciadas en enfermería:

2 asistenciales y 1 gestora

- Auxiliares de enfermería: 5

- Auxiliares de servicio: 3

- Químicos farmacéuticos: 2

- Auxiliares de farmacia: 2

\section{Institución pública III}

- Licenciadas en enfermería:

4 asistenciales y 1 gestora

- Auxiliares de enfermería: 5

- Auxiliares de servicio: 4

- Químicos farmacéuticos: 2

- Auxiliares de farmacia: 0

\section{Institución pública IV}

- Licenciadas en enfermería:

1 asistencial y 1 gestora

- Auxiliares de enfermería: 8

- Auxiliares de servicio: 2

- Químicos farmacéuticos: 1

- Auxiliares de farmacia: 0

\section{Institución privada I}

- Licenciadas en enfermería:

5 asistenciales y 1 gestora

- Auxiliares de enfermería: 20

- Auxiliares de servicio: 10

- Químicos farmacéuticos: 2

- Auxiliares de farmacia: 0
- Licenciadas en enfermería:

5 asistenciales y 1 gestora

- Auxiliares de enfermería: 12

- Auxiliares de servicio: 5

- Químicos farmacéuticos: 2

- Auxiliares de farmacia: 0

\section{Institución privada III}

- Licenciadas en enfermería:

3 asistenciales y 1 gestora

- Auxiliares de enfermería: 10

- Auxiliares de servicio: 3

- Químicos farmacéuticos: 1

- Auxiliares de farmacia: 0

\section{Institución privada IV}

- Licenciadas en enfermería:

1 asistencial y 1 gestora

- Auxiliares de enfermería: 3

- Auxiliares de servicio: 1

- Químicos farmacéuticos: 4

- Auxiliares de farmacia: 0

La muestra por conveniencia estuvo conformada por 145 profesionales y técnicos de salud de las 8 instituciones, entre ellos 32 licenciadas en enfermería, 76 auxiliares de enfermería, 8 químicos farmacéuticos, 2 auxiliares de farmacia y 27 auxiliares de servicio.

Para la fase cualitativa se conformó grupos de profesionales y técnicos de salud de las 8 instituciones de salud, según las funciones establecidas en el manejo de las drogas peligrosas.

La selección del número de Instituciones, así como su ubicación se realizó tomando en cuenta que el departamento de Montevideo (capital del país) concentra al $60 \%$ de la población nacional.

Dentro de las Instituciones que integran el estudio, la Institución pública I atiende población pediátrica y centraliza a todos los niños del país que 
son asistidos por el sistema público. Siendo este centro de referencia pediátrico a nivel nacional para las instituciones públicas y privadas. Brindan a todos los niños y adolescentes con cáncer del Uruguay, tratamiento, atención e investigación médica. Los pacientes asistidos en este centro reciben tratamiento de manera gratuita para sus familias. Absolutamente todos los costos son absorbidos por una fundación sin fines de lucro y contando con el fuerte aporte de la Administración de los Servicios de Salud del Estado (ASSE) y con el apoyo invalorable de toda la sociedad.

La Institución pública II es un hospital al servicio de la vida, creado hace más de 100 años, responsable de la atención de todo el personal militar en actividad, retirado y de sus familias, donde el pilar fundamental es mantener al máximo el potencial humano de las Fuerzas Armadas, en buenas condiciones de salud, a través de medidas preventivas y tratamientos médicos. La población asistida es de 152.875 usuarios y abarca a todo el país. Es un hospital general que cuenta con todas las especialidades, entre ellas la oncología.

La Institución pública III corresponde a un hospital universitario, donde la población beneficiaria proviene de ASSE en su mayoría, sistemas grupales de salud, como el de los funcionarios de la Universidad de la República y eventualmente otros que opten por recibir atención en el Hospital Universitario.

La Institución pública IV, es un prestador de servicios públicos dependiente de ASSE. Es un hospital con especialidad oncológica para adultos, es Centro de Referencia del Sistema de Servicios de Salud del Ministerio de Salud Pública a nivel nacional. Brinda servicios en primer y segundo nivel de atención. La población total de ASSE asciende a 1.119.06, incluyendo niños y adultos, en esta población entran los usuarios de la Institución pública I, III y IV.

Respecto a las privadas, se toman cuatro instituciones de la ciudad de Montevideo por ser las más representativas debido al número de usua- rios que atienden, tanto en cantidad de niños como de adultos. Dichas Instituciones son prestadoras de Servicios de Salud y no solo cubren la ciudad de Montevideo, sino que llegan a todo el país mediante filiales y/o sucursales.

La Institución privada I asiste 283.198 usuarios, la II a 176.073, la III 76.274 y la IV a 63.983, del total de la población del país.

\section{Variables del estudio}

Drogas peligrosas: grupo de medicamentos con mecanismos de acción muy diversos, pero con la característica común de interrumpir el ciclo celular en alguna de sus fases. Esta propiedad permite utilizarlos en el tratamiento de enfermedades neoplásicas como terapia única o en combinación con radioterapia y/o cirugía (1).

Bioseguridad: entendida como un conjunto de normas y procedimientos considerados seguros y adecuados para la manutención de la salud de los trabajadores en la realización de actividades de riesgos. En el contexto de la salud, la bioseguridad está íntimamente relacionada con la seguridad de los cuidados brindados a las personas y a las buenas prácticas (29).

\section{Recursos humanos}

El personal que se encarga del manejo de las drogas peligrosas: licenciadas en enfermería, auxiliares de enfermería, auxiliares de servicio, químico farmacéutico, auxiliar de farmacia.

\section{Recursos materiales}

Equipo de protección personal. Está dirigido a evitar un posible contacto o absorción del producto a través de las vías de exposición. Es el uso de:

- Guantes de látex o de otro material que se haya comprobado permeabilidad a las drogas utilizadas. Doble par.

- Bata impermeable con mangas largas y puños elásticos ajustados, cerrada adelante (único uso). 
- Tapaboca de protección respiratoria con filtros para "polvos y neblinas" (N95).

- Gorro.

- Zapatones.

\section{Recursos estructurales}

Cabinas de Seguridad Biológica (CSB): Una cabina de flujo laminar, cámara de flujo laminar o campana de flujo laminar es un recinto que emplea un ventilador para forzar el paso de aire a través de un filtro HEPA o ULPA y proporcionar aire limpio a la zona de trabajo libre de partículas de hasta 0.1 micras (figura 1). Este tipo de equipo se fabrica en forma generalmente prismática con una única cara libre (la frontal) que da acceso al interior, donde se localiza la superficie de trabajo, que normalmente permanece limpia y estéril. El área de preparación de citostáticos debe estar ubicada en una zona restringida, de poco acceso, solo para personal autorizado. La centralización de la preparación de estos productos garantiza una mayor seguridad para el trabajador y el medio ambiente, reduciendo en gran medida el riesgo de exposición. Debe estar dividida en dos zonas, una semilimpia (zona de acceso restringido para el almacenamiento de sueros y material de preparación) y la zona limpia donde se encuentra ubicada la CSB.

- El área limpia es el sector donde se realiza la elaboración. Debe contar con una cabina de bioseguridad de F.L. vertical Clase II.

- La antecámara es el sector en que se acondicionan los materiales y medicamentos que ingresan al área de reconstitución y donde el personal se coloca el equipo de protección personal antes de ingresar al área limpia.

- Área administrativa destinada a la recepción de las prescripciones, archivo de documentos y todo lo relativo a registros, puede ser una zona de almacenamiento de sueros, medicamentos, insumos de trabajo.

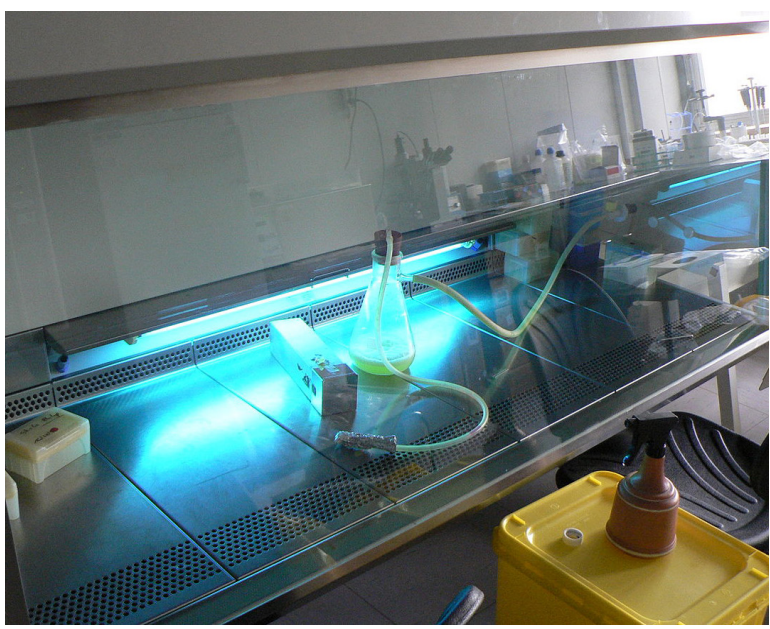

Figura 1. Cabina de Seguridad Biológica.

\section{Procesos}

Recepción: las drogas peligrosas deben ser recepcionadas por personal debidamente formado y capacitado, el cual deberá usar el equipo de protección personal adecuado para evitar contaminación. Deberá luego almacenarlas de acuerdo a lo que indica el fabricante.

Almacenamiento: las drogas peligrosas siempre deben ser almacenadas separadas de otras drogas. Deben ser colocadas en un área con excelente ventilación y extracción del aire suficiente para diluir aerosoles y partículas contaminadas.

Guardar las drogas en cajones o compartimientos con delanteros altos y de tamaño suficiente para contener todas las drogas.

Los estantes deben tener barandas para la prevención de la caída inadvertida de los cajones de las drogas.

Preparación: la preparación de las drogas peligrosas debe ser realizada en una cabina de flujo laminar. El operador deberá usar adecuadamente el equipo protector para tal fin (uso de bata, tapaboca, guantes, gorro y zapatones), y debe tener conocimiento de las drogas, conocer dilución, estabilidad, entre otros. Saber cómo actuar frente a un derrame de citostáticos y tomar las medidas preventivas adecuadas. 
Administración: durante la administración de drogas peligrosas por vía parenteral el personal de enfermería debe usar equipo protector (guantes, bata, gorro, tapaboca). Tomar todas las medidas preventivas para evitar derrames o cualquier accidente que lo exponga a la contaminación.

Desecho de los residuos: los residuos citotóxicos se encuentran dentro de los residuos de riesgo o específicos, que son aquellos que por sus características y grado de contaminación química o biológica requieren un tratamiento específico y diferenciado de los residuos "urbanos" tanto fuera como dentro del centro. Se considera residuo citotóxico tanto los restos de medicamentos citostáticos como todo el material que ha estado en contacto con ellos. Proceden principalmente de restos de medicamentos citotóxicos generados en la preparación y administración; material cortante y/o punzante utilizado en la preparación y administración de éstos, material sanitario de un solo uso que ha estado en contacto con los medicamentos y que contiene trazas de sustancias citotóxicas, material de protección contaminado de los manipuladores, material utilizado para la limpieza de la zona de preparación y para el tratamiento de derrames.

\section{Instrumentos para la recolección de los datos}

Un formulario para la caracterización de los recursos humanos, materiales y estructurales y un formulario para la identificación de los procesos en el manejo de las drogas peligrosas en cuanto a la recepción, almacenamiento, preparación, administración y desecho de los residuos según el personal de salud involucrado.

El primer formulario estuvo conformado por: identificación de la Institución de Salud (un ítem); identificación de los recursos humanos (cinco ítems) relacionados a la recepción, almacenamiento, preparación, administración y desechos de drogas peligrosas; identificación de recursos estructurales (cinco ítems), desarrollados de acuerdo a las dife- rentes etapas de recepción, almacenamiento, preparación, administración y desechos; por último, la identificación de los recursos materiales en las mismas etapas (cuatro ítems).

El segundo formulario estuvo conformado por: identificación de la institución de salud (un ítem) y los datos relacionados a los procesos de recepción, almacenamiento, preparación, administración y desechos de las drogas peligrosas (cinco ítems).

Para la validación del contenido de los formularios, se conformó un comité de jueces constituido por tres profesionales de salud expertos en el tema del manejo de las drogas peligrosas. A los jueces seleccionados se les facilitó la batería de ítems del formulario. Estimaron los ítems pertinentes para caracterizar los recursos humanos, materiales y estructurales e identificar los procesos de recepción, almacenamiento, preparación, administración y desecho de los residuos de las drogas peligrosas, mediante la observación.

Fue realizada una revisión entre el grupo de expertos y la investigadora no siendo necesario la realización de cambios en los instrumentos.

\section{Procedimientos para la recolección de los datos}

Los datos fueron recolectados en el periodo comprendido entre mayo y julio de 2016. Para la caracterización de los recursos humanos, materiales y estructurales involucrados en el manejo de las drogas peligrosas de las ocho instituciones, se aplicó el formulario a través de la observación por la propia investigadora.

Para los recursos humanos de las ocho instituciones se observó quién era el responsable en cada una de ellas de recepcionar y almacenar las drogas, de prepararlas, administrarlas y desecharlas. Se concurrió en los diferentes turnos de trabajo dependiendo de si era área de internación y/o ambulatoria para observar a todos los profesionales y técnicos de salud. Se visitó en más de una oportunidad para poder visualizar las diferentes activida- 
des en diferentes horarios ya que estas variaban de acuerdo a la hora del día. En algunas instituciones la reposición del material se hacía por la mañana y en otras por la tarde, y en las instituciones que cuentan con área de internación, ésta se realizaba en cualquiera de los cuatro turnos, por lo que se acudió en la mañana, la tarde, en el vespertino y en la noche, debido a que los turnos en las áreas de internación son de seis horas. En las áreas ambulatorias el horario de funcionamiento es durante el día, existiendo dos turnos.

En cuanto a los recursos materiales se observó el lugar donde almacenaban los materiales limpios y se identificó cada uno de los materiales existentes en la institución, verificando con lo que contaba cada institución para las diferentes actividades. Además, se preguntó a la enfermera gestora si contaban con más material en otro sitio o si necesitaban algo específico, dónde lo podían conseguir. Respecto a la caracterización de la infraestructura se realizó una observación también por parte de la investigadora en todas las instituciones de salud involucradas en el estudio. Se visitó a todas ellas y se identificaron los recursos de infraestructura de las áreas de recepción y almacenamiento, preparación, administración y desechos.

Para la identificación de los procesos en cada fase del manejo de las drogas, se realizó una observación estructurada y no participante a todos los colaboradores del estudio.

Antes del inicio de la recolección de los datos, se realizó una reunión con todos los involucrados del estudio, donde se les explicó los objetivos de la investigación y la forma de recolección de los datos la cual sería mediante la observación. Se les solicitó la participación y consecuente firma de un consentimiento informado. El personal del equipo que no aceptó participar del estudio no fue observado.

El periodo de aplicación fue de dos meses y las visitas se realizaron más de una vez por día dependiendo del horario de funcionamiento del centro. En las áreas de internación se visitó también durante los fines de semana.
Los datos fueron almacenados y analizados en el programa Microsoft Office Excel 2007. Se realizó un análisis descriptivo con frecuencia relativa y absoluta de las variables.

Para conocer la percepción de los riesgos y las dificultades en el manejo de las drogas peligrosas según el personal de salud, se utilizó la técnica del grupo focal. Se optó por los grupos focales por tratarse de una técnica adecuada para estudiar temas relacionados a las representaciones y relaciones de diferentes grupos profesionales y procesos de trabajo $(36,37)$.

Fueron conformados cuatro grupos y para la composición de los mismos se consideró los siguientes criterios de inclusión: que tuvieran el mismo rol establecido en el manejo de las drogas, que pertenecieran al mismo sistema de salud (publico/ privado) y que representaran a las ocho instituciones de salud:

Grupo I (GF1): cuatro licenciados en enfermería (LE), cuatro auxiliares de enfermería (AE), cuatro auxiliares de servicio (AS) /institución pública.

Grupo II (GF2): tres químicos farmacéuticos (QF), dos auxiliares de farmacia (AF) /institución pública.

Grupo III (GF3): cuatro licenciados en enfermería (LE), cuatro auxiliares de enfermería (AE), cuatro auxiliares de servicio (AS) /institución privada.

Grupo IV (GF4): cinco químicos farmacéuticos (QF) /institución privada.

El reclutamiento de los participantes fue por azar, pues se trataba de un universo homogéneo en cuanto a los roles. La invitación fue por escrito dos semanas antes del encuentro. A cada uno de los participantes se les explicó los objetivos y procedimientos de la investigación y se solicitó la firma del consentimiento informado.

Una semana antes del encuentro se les contactó por teléfono, coordinando para la semana siguiente. El día previo se confirmó la asistencia vía telefónica, confirmando el $100 \%$ de los invitados a los grupos focales, encuentros que se realizaron 
en días distintos, en la sala de reuniones de una de las instituciones de salud participantes del estudio, que facilitó el lugar.

La investigadora cumplió el rol de moderadora asegurando una direccionalidad en la discusión de los temas con una adecuada flexibilidad, que permitió la aparición de opiniones divergentes enriquecedoras para la discusión. Además, participó un observador que ayudó al moderador en la conducción del grupo, tomó nota de las principales impresiones verbales y no verbales, además de ocuparse con el equipo de grabación.

Para las preguntas se utilizó un guión semi estructurado:

- ¿Cómo ha sido su experiencia en el manejo de las drogas peligrosas?

- ¿Cuáles han sido las dificultades en su trabajo cotidiano con las drogas peligrosas?

- En esta experiencia del manejo de las drogas peligrosas, ¿cómo percibe los riesgos?

Se realizaron dos sesiones con cada grupo hasta que no hubo más informaciones nuevas. Cada sesión duró de 60 a 90 minutos y fueron grabadas.

\section{Análisis de los discursos}

Se realizó análisis temático con base en categorías con los siguientes pasos (38):

- Posterior a la transcripción, se realizaron lecturas atentas y cuidadosas hasta aprender el sentido global de los discursos.

- Se inició la codificación abierta con la intención de asignar etiquetas para separar y reordenar los datos.

- Los datos fueron separados en unidades significativas mediante etiquetas.

- Luego estas unidades significativas fueron agrupadas en categorías.

\section{Aspectos éticos}

Esta investigación fue regida por los siete Principios de Ezequiel Emanuel (39):

Valor: los conocimientos de este estudio generaron una línea de base para la propuesta de medidas de bioseguridad basadas en los mejores estándares internacionales, pero que respondieron a la realidad local de Uruguay. Además, se generaron conocimientos relacionados a la práctica de enfermería que posibilitaron nuevos enfoques de cuidados más seguros.

Validez Científica: la investigación tuvo un objetivo científico claro, estuvo diseñada usando principios, métodos y prácticas de efecto seguro aceptados. Tuvo poder suficiente para probar definitivamente los objetivos, un plan de análisis de datos verosímil y pudo llevarse a cabo. La validez como requisito ético incluyó: la adecuada utilización de recursos y evitó la explotación.

Selección equitativa del sujeto: la identificación y la selección de los sujetos potenciales que participaron en la investigación fueron equitativos. La selección fue basada en los objetivos y no en las desigualdades sociales. Hubo oportunidad de participación para todos los grupos. Interacción dinámica entre la selección equitativa y la garantía de una razón costo-beneficio apropiada.

Proporción favorable de riesgo-beneficio: no hubo riesgos para los participantes. La investigación generó informaciones respecto a las medidas de bioseguridad en el manejo de las drogas peligrosas del sistema de salud de Uruguay.

Evaluación independiente: esta investigación fue aprobada y certificada por el Comité de Ética Científico de la Facultad de Enfermería de la Universidad Andrés Bello.

Consentimiento informado: la finalidad del consentimiento informado fue asegurar que los individuos participaran en la investigación propuesta solo si ésta era compatible con sus valores, intereses y preferencias. Los requisitos del con- 
sentimiento informado incluyeron en proveer la información sobre la finalidad, los riesgos, los beneficios y las alternativas a la investigación, una debida comprensión por parte del sujeto de esta información y la toma de una decisión voluntaria.

Respeto a los sujetos inscritos: esta investigación respetó a los sujetos desde el principio de la beneficencia y la autonomía. Se propuso al participante retirarse del estudio en cualquier momento, se garantizó la confidencialidad y se ofreció informaciones sobre los riesgos y beneficios.

\section{RESULTADOS}

De un total de 188 profesionales y técnicos de salud de las ocho instituciones de salud involucrados en el manejo de las drogas peligrosas, 145 participaron del estudio, entre ellos, 76 (52,4\%) auxiliares de enfermería, $32(22,1 \%)$ licenciados de enfermería, 27 (18,6\%) auxiliares de servicio, 8 (5,5\%) químicos farmacéuticos y $2(1,4 \%)$ de auxiliares de far- macia. Cabe destacar que, de los 145 participantes, $71(49 \%)$ pertenecían a las instituciones públicas y $74(51 \%)$ a las instituciones privadas (figura 2). El $100 \%$ de las instituciones dispone de un área accesible solo a personal autorizado para la preparación de las drogas peligrosas; y cuenta con refrigerador destinado exclusivamente a las drogas peligrosas. De estos refrigeradores sólo un $25 \%$ cuenta con termómetro y el restante $(75 \%)$ con termómetro y alarma.

Las drogas en un $62,5 \%$ son almacenadas en estanterías comunes y un $37,5 \%$ en estanterías con barandas; las drogas son preparadas un $12,5 \%$ en la farmacia y el $87,5 \%$ en áreas con cabina y ante cámara especialmente diseñadas para tal uso.

En cuanto a los requisitos que necesita el local donde se prepara las diferentes drogas, se observó que un $37,5 \%$ de las instituciones cumple el $100 \%$ de lo requerido. Un $12,5 \%$ cumple un $75 \%$ de ese requerimiento y el restante cumple el $50 \%$ de los requerimientos.

\begin{tabular}{|c|c|c|c|c|c|c|c|c|c|c|}
\hline \multirow{2}{*}{ Recursos humanos } & \multicolumn{2}{|c|}{ Personal recibe } & \multicolumn{2}{|c|}{ Personal almacena } & \multicolumn{2}{|c|}{ Personal prepara } & \multicolumn{2}{|c|}{ Personal administra } & \multicolumn{2}{|c|}{ Personal desecha } \\
\hline & $N^{\circ}$ & $\%$ & $N^{\circ}$ & $\%$ & $N^{\circ}$ & $\%$ & $\mathrm{~N}^{\circ}$ & $\%$ & $N^{\circ}$ & $\%$ \\
\hline Licenciado en enfermería & 0 & 0 & 0 & 0 & 1 & 12,5 & 0 & 0 & 0 & 0 \\
\hline Auxiliar de enfermería & 0 & 0 & 0 & 0 & 4 & 50 & 0 & 0 & 0 & 0 \\
\hline Químico farmacéutico & 0 & 0 & 1 & 12,5 & 0 & 0 & 0 & 0 & 1 & 12,5 \\
\hline Auxiliar de farmacia & 0 & 0 & 0 & 0 & 1 & 12,5 & 0 & 0 & 0 & 0 \\
\hline Auxiliar de servicio & 0 & 0 & 0 & 0 & 0 & 0 & 0 & 0 & 1 & 12,5 \\
\hline Licenciado y auxiliar de enfermería & 4 & 50 & 3 & 37,5 & 2 & 25 & 8 & 100 & 1 & 12,5 \\
\hline Químico farmacéutico y auxiliar de farmacia & 1 & 12,5 & 1 & 12,5 & 0 & 0 & 0 & 0 & 0 & 0 \\
\hline $\begin{array}{l}\text { Licenciado en enfermería, auxiliar de enfermería } \\
\text { y químico farmacéutico }\end{array}$ & 2 & 25 & 2 & 25 & 0 & 0 & 0 & 0 & 3 & 37,5 \\
\hline Químico farmacéutico y auxiliar de enfermería & 1 & 12,5 & 1 & 12,5 & 0 & 0 & 0 & 0 & 1 & 12,5 \\
\hline $\begin{array}{l}\text { Licenciado y auxiliar de enfermería, químico } \\
\text { farmacéutico y auxiliar de servicio }\end{array}$ & 0 & 0 & 0 & 0 & 0 & 0 & 0 & 0 & 1 & 12,5 \\
\hline Total & 8 & 100 & 8 & 100 & 8 & 100 & 8 & 100 & 8 & 100 \\
\hline
\end{tabular}

Figura 2. Distribución del número y porcentaje de los recursos humanos según el manejo de drogas peligrosas de las 8 instituciones de salud. 
El 100\% de las instituciones dispone de bolsa roja y descartex para los desechos de residuos y las drogas son administradas en áreas de hospital de día e internación.

El proceso de análisis de contenido permitió la generación de tres categorías:

1. Dificultades en el manejo de las drogas peligrosas

Fue posible identificar por medio de los relatos las dificultades relacionadas a recursos humanos, materiales y de infraestructura, además de debilidades en el conocimiento, ausencia de protocolos, debilidades en las capacitaciones, la falta de apoyo institucional y ausencia de un marco regulatorio relacionado al manejo de las drogas peligrosas a nivel nacional. En cuanto a la infraestructura, no todas las instituciones cuentan con un área adecuada para la preparación de las drogas peligrosas. Es posible verificar por los relatos que no es suficiente contar con la cabina de seguridad biológica, sino que es igualmente importante la zona en que se encuentra y las condiciones de esta área. Estar afuera del área de donde se administran las drogas, hace que no se cumplan los horarios estipulados y al tener que trasladar dichas drogas de un edificio a otro las medidas de bioseguridad empleadas no cumplen con los requisitos.

Se explicitan las dificultades relacionadas a la falta de materiales adecuados para las diversas fases del manejo de las drogas peligrosas. También se observa que además de la falta de material adecuado, la falta de entrenamiento del personal agrava esta condición.

No contar con personal adiestrado, formado y con los mínimos conocimientos para desempeñarse en el área es una dificultad latente. El personal se va formando en la misma práctica, con el personal ya existente y con la colaboración del resto del equipo.

Falta de conocimiento y capacitación formal para el personal: el personal es preparado por el equipo que ya está cumpliendo funciones en el área, o mediante su propia formación, lo que hace que todos trabajen de forma distinta.

El desconocimiento conduce al descuido y por lo tanto a la exposición de riesgos relacionados a la incorrecta manipulación de estas drogas. Relacionado al desconocimiento, los relatos explicitan la falta de protocolos para el manejo de las drogas. Si estos existieran podrían trabajar con mayor seguridad, evitando riesgos hacia su persona, hacia el resto del equipo de salud y hacia el usuario. Contar con los protocolos ayudaría a todo el equipo de enfermería a cumplir adecuadamente con su trabajo y a tener las medidas de bioseguridad ya que a veces no las aplican por desconocimiento. Los protocolos son para que todos trabajen de forma homogénea.

La falta de capacitaciones se relaciona con no contar con personal adiestrado, formado y con los mínimos conocimientos para desempeñarse en el área. Asumen la falta de conocimiento y refieren la necesidad de actividades formativas.

El personal que atiende a estos pacientes a veces no es del área, debido a que se internan pacientes en otros sectores y esto hace deficiente la falta de capacitación, ya que este personal no se dedica exclusivamente a atender pacientes de la especialidad.

Otra dificultad que se verificó en esta categoría fue la falta de apoyo institucional, debido a que no hay nada regulado. Esto hace que las instituciones no apoyen al personal porque no hay una concientización de la importancia del tema. La ausencia de marco regulatorio a nivel nacional; en Uruguay, no existe una legislación para el manejo de las drogas peligrosas, lo que dificulta aún más porque cada institución trabaja según su criterio y conocimiento.

\section{Percepción de Riesgos}

El personal que maneja las drogas peligrosas reconoce los riesgos y tiene la conciencia de que siempre están presentes. Articulan la minimización de ellos con el conocimiento, capacitaciones 
y existencia de protocolos. Reconocen que los efectos a largo plazo dificultan la concientización del personal en cuanto al manejo adecuado de estas drogas retomando nuevamente el tema del desconocimiento. Relacionado a la falta de medidas de seguridad en el manejo de las drogas peligrosas, los relatos explicitan que a veces se cuentan con ellas y no las saben usar o no las usan por desconocimiento.

3. Logros obtenidos en el manejo de las drogas peligrosas

Los logros caracterizados por la autoformación fueron más bien por esfuerzo personal. En cuanto a recursos materiales y de infraestructura, el personal ha conquistado negociando con las instituciones a lo largo de los años.

\section{DISCUSIÓN}

Los recursos humanos, materiales y estructurales, además de los procesos identificados en este estudio en el manejo de las drogas peligrosas, serán discutidos a la luz de los estándares internacionales (14-22).

En relación a los recursos humanos, en las ocho Instituciones de salud, se pudo observar que las drogas peligrosas eran recibidas y almacenadas por diferentes profesionales. En cuatro instituciones recibían las licenciadas y las auxiliares de enfermería, en una el químico farmacéutico y auxiliar de farmacia, en dos, las licenciadas en enfermería, auxiliar de enfermería y químico farmacéutico y en una el químico farmacéutico y auxiliar de enfermería. Los estándares internacionales recomiendan a los químicos farmacéuticos exclusivamente a cargo de este proceso (18-21). En ninguna de las instituciones de salud los químicos farmacéuticos preparan las drogas peligrosas. Esta función está a cargo del personal de enfermería y de auxiliares de farmacia, siendo los más expuestos, ya que, manipulan las drogas en todas las etapas del proceso. En las ocho Instituciones de Salud, las drogas peligrosas eran ad- ministradas por las licenciadas en enfermería y/o auxiliares de enfermería, lo que está acorde a los estándares internacionales (14-22).

En el desecho de los residuos de las drogas peligrosas participaba todo el equipo de salud, ya sean licenciadas en enfermería, químicos farmacéuticos, auxiliares de enfermería, auxiliares de farmacia o auxiliares de servicio, en las diferentes etapas del proceso. Esto se observó en las ocho instituciones de Salud y está regido por la normativa existente del Ministerio de Salud Pública de Uruguay, la cual es responsable del proceso de desecho de las Instituciones de Salud (40), lo que hace que esté regulado y acorde a los estándares internacionales (14-22).

Referente a los recursos materiales, el uso adecuado del equipo de protección personal es una de las mejores formas de prevenir la exposición ocupacional de los trabajadores frente a las drogas peligrosas. Por eso la prevención en todos los procesos es un punto fundamental. La indumentaria necesaria está compuesta por bata, guantes, gorro, mascarilla, gafas y zapatones. El uso de estos materiales va acorde a la función que se esté desarrollando. Para la recepción y almacenamiento de dichas drogas el equipo necesario es: guantes, sobre túnica impermeable y tapaboca triple filtro. En tres de las instituciones participantes se observó que usaban sobre túnica impermeable, en las otras cinco usaban la sobre túnica que tenían disponible en el servicio, (impermeable, de tela o reciclada). Los guantes de látex o vinilo son los recomendados por los estándares internacionales y se pudo observar que en las ocho instituciones lo usaban indistintamente, según disponibilidad, no basándose en ningún estándar. En cuanto al uso de mascarillas, la recomendada en este proceso es la de triple filtro y se pudo apreciar en las diferentes instituciones que usaban de triple filtro, N95 o comunes, pero no tenían estipulado el uso de una específica (18-21). El equipo de protección personal está dirigido a evitar un posible contacto o absorción de las dro- 
gas a través de la exposición, por eso la importancia del mismo $(14,22)$.

Para la preparación de las drogas peligrosas, se comprobó que en cinco instituciones usaban batas impermeables, en una impermeable común, en otra impermeable común o de tela según con lo que contaban en el servicio y en solo una se usaba bata de quimioterapia, la cual es la recomendada por los estándares internacionales. En ninguna de las ocho Instituciones se usaban guantes diseñados para quimioterapia como lo recomiendan los estándares internacionales, pero la razón más importante del no uso es que no existen en el mercado nacional. En seis de las instituciones se observó el uso de gafas de protección ocular para evitar posibles contactos con drogas y minimizar la exposición, como es lo recomendado por los estándares internacionales. El uso de zapatones solo se vio en tres instituciones, siendo los mismos recomendados por los estándares internacionales (18-21).

En la preparación de las drogas peligrosas el personal puede quedar expuesto a estos agentes, que están presentes en el aire, en las superficies de trabajo y/o en la ropa entre otras cosas, por tal motivo es fundamental el cumplimiento de los estándares de seguridad relacionados al manejo de estas drogas (15-17,24-26).

La administración de las drogas peligrosas, en las ocho instituciones de salud estaba a cargo el personal de enfermería como recomiendan los estándares internacionales. Para la administración en cuanto al uso del equipo de protección personal, se pudo observar disparidades en las ocho Instituciones, debido a que no hay un protocolo que se lleve a cabo como sugieren los estándares internacionales, esto lleva a que en cada institución se trabaje de diferente forma y no se use el equipo de protección personal recomendado. Con relación al uso de las batas para la administración de las drogas peligrosas, se usaban en dos de las Instituciones las descartables e impermeables. En las seis restantes usaban impermeables, comu- nes y/o descartables según con lo que contaban en el servicio, no cumpliendo con las recomendaciones de los estándares, sino de acuerdo a la disponibilidad que tenía la institución. Con el uso de guantes para la administración se observó que usaban lo que tenían disponible en el servicio y/o institución, sin embargo, el uso de los mismos fue en el $100 \%$ de los casos, aunque no eran los más recomendados por los estándares internacionales. En una institución usaban para la administración guantes quirúrgicos estériles y en las otras siete usaban quirúrgicos estériles y de látex. En cinco instituciones usaban gafas como recomiendan los estándares y en tres no usaban ningún tipo de protección para la cara. El uso de la protección ocular durante la administración protege de posibles salpicaduras y accidentes. El uso de tapaboca triple filtro que es el que recomiendan los estándares para esta etapa, lo usaban en cinco de las instituciones de salud. En tres usaban el que tenían disponible, que podía ser de triple filtro o común (18-21).

Acerca del uso de zapatones se observó que en solo dos de las Instituciones lo usaban. En las recomendaciones de los estándares internacionales, para la administración no hacen referencia al uso de estos (20).

En referencia a los desechos de los residuos de las drogas peligrosas en todas las instituciones se cumplen con los estándares, para la eliminación de los mismos (18-21).

Esto es debido a que lo rige el Ministerio de Salud Pública de Uruguay (40), para todas las instituciones de salud, sean públicas o privadas.

En cuanto a los recursos estructurales se pudo observar que las ocho instituciones cuentan con área accesible para el manejo de estas drogas exclusivamente, como lo recomiendan las normativas internacionales. El área de preparación de las drogas peligrosas debe estar ubicada en una zona restringida, de poco acceso, solo para personal autorizado. Centralizar la preparación de estas drogas garantiza mayor seguridad para los trabajadores y el medio ambiente (18-21). 
Se observó que contaban con refrigerador específico para las drogas peligrosas, pero que solo en seis contaban con termómetro y alarma como lo disponen los estándares internacionales. Pero dos de las instituciones tenían solo termómetro y no contaban con alarma $(19,21)$. Las estanterías que se usaban para almacenar las drogas no todas tenían barandas para evitar caídas, solo tres de ellas contaban con este recurso estructural (14-22).

Todas las instituciones contaban con Cabina de Seguridad Biológica. Las mismas se encontraban ubicadas en área restringida, existiendo dos zonas, una semilimpia (zona de acceso restringido para el almacenamiento de sueros y material de preparación) y una zona limpia donde estaba la cabina de seguridad biológica, acorde a las recomendaciones internacionales (18-21).

Debilidades de los recursos humanos, materiales y de infraestructura para la preparación, administración y eliminación de las drogas peligrosas conllevan a la exposición de diversos profesionales de la salud, pero la evidencia refiere al personal de enfermería como el mayor expuesto, en especial en la etapa de preparación, por eso tanto hincapié en la protección desde todo punto de vista $(15,17)$. Lo anterior nos indica claramente que se debe aplicar un sistema de trabajo apropiado para prevenir posibles efectos secundarios. Diferentes organismos de reconocimiento mundial, encargados de proteger la salud y seguridad de los trabajadores de la salud han publicado recomendaciones internacionales (18-21).

Sin embargo, Uruguay no cuenta con políticas públicas relacionadas a modelos de seguridad que contemplen precauciones que se deban tomar para evitar riesgos. La única normativa que existe vigente en el país es sobre la gestión de los residuos hospitalarios (40).

En relación al proceso de recepción y almacenamiento, preparación, administración, desecho y derrames de drogas peligrosas se realizó una observación estructurada y no participante por la propia investigadora de las actividades realizadas en dichos procesos. Fueron observados 32 licenciadas en enfermería, 76 auxiliares de enfermería, 8 químicos farmacéuticos, 2 auxiliares de farmacia y 27 auxiliares de servicio.

El $100 \%$ de las licenciadas en enfermería en el proceso de recepción y almacenamiento de las drogas peligrosas realizó previamente lavado de manos, lo cual está acorde a las recomendaciones de los estándares internacionales (18-21).

Respecto al uso de sobre túnica, guantes y tapaboca triple filtro para manipular las drogas, guardar las drogas en área específica y desechar el equipo en bolsa roja, además del lavado al finalizar el procedimiento hubo un cumplimiento que fluctuó de $12,5 \%$ a $75 \%$, siendo el menor cumplimiento el uso de la sobre túnica y el mayor cumplimiento en el uso de guantes.

Se observó que existe un uso inadecuado o no uso del equipo de protección total. El equipo de protección personal es una de las formas de prevenir la exposición ocupacional de los trabajadores frente a drogas peligrosas. La prevención supone un punto clave en todas las etapas del proceso, si no se cumple en alguna de estas etapas de forma adecuada, la protección no es segura (18-21), lo cual no está acorde a las normativas internacionales y se exponen a estas drogas sin medidas adecuadas de bioseguridad $(14,22)$, con los consiguientes riesgos $(9,10)$.

En relación a las actividades de preparación de las drogas peligrosas el $100 \%$ de las licenciadas en enfermería se lavaban las manos, revisaban las prescripciones médicas, reunían el material necesario antes de ir a realizar el procedimiento y preparaban las drogas dentro de la cabina de flujo laminar, lo que está acorde a los estándares internacionales. Además, previene y reduce los riesgos laborales y ambientales ocasionados por gestión inadecuada. En el uso de sobre túnica para quimioterapia, doble par de guantes de vinilo, tapaboca N95, gafas y zapatones, se observó un cumplimiento desde $21,9 \%$ hasta $62,5 \%$, 
nuevamente no cumpliendo con las recomendaciones de los estándares internacionales $(14,22)$. En cuanto a la administración de drogas peligrosas los estándares internacionales recomiendan el uso del equipo de protección personal en el $100 \%$ de los casos, pero se observó que el $34,4 \%$ de las licenciadas en enfermería usaban guantes de vinilo, $28,1 \%$ sobre túnica impermeable, además del no cumplimiento de la utilización del tapaboca triple filtro, ya que solo lo usaban un $54,4 \%$.

En el proceso de desechos de residuos de las drogas peligrosas las licenciadas en enfermería no cumplen con todos los estándares internacionales. 93,8\% usaban guantes de limpieza, $31,25 \%$ usaban tapaboca triple filtro y solo un $21,9 \%$ usaban sobre túnica impermeable. En el proceso de derrame de drogas peligrosas en las ocho instituciones, existe protocolo de actuación frente a un derrame y está acorde a lo que recomiendan los estándares internacionales, lo que indica un mayor cumplimiento en esta actividad. El personal de enfermería está a cargo, involucrado en todas las etapas del proceso; desde la recepción, almacenamiento, preparación, administración y desechos de residuos, por lo tanto, es el más expuesto, por este motivo debe tener un perfil muy concreto, debe ser experto y tener conocimientos muy amplios sobre la especialidad. Todo el personal que recepciona y almacena las drogas peligrosas puede sufrir exposición laboral, si no toma las medidas de protección recomendadas por los estándares internacionales, es decir, que los auxiliares de enfermería no están ajenos a esta realidad $(18,21)$.

96\% de los auxiliares de enfermería en el proceso de recepción y almacenamiento de las drogas peligrosas realizó previamente lavado de manos, lo cual se aproxima a lo que recomiendan los estándares internacionales, pero no se logra un cumplimiento absoluto que es lo esperado.

En cuanto al uso de sobre túnica hay un incumplimiento total. Un $72,4 \%$ usan guantes y solo un $4 \%$ tapaboca triple filtro para manipular las drogas, guardar las drogas en área específica y desechar el equipo en bolsa roja, además del lavado al finalizar el procedimiento.

Vemos que no se cumple con las recomendaciones de los estándares internacionales, como debería ser, para garantizar mejores medidas de bioseguridad. Si bien nada asegura el 100\% de protección, si se cumplen con las recomendaciones se previenen a futuro posibles complicaciones (14-22, 24-26).

En seis instituciones, los auxiliares de enfermería preparan las drogas peligrosas exclusivamente, lo que no está acorde a los estándares (14-22). De los 76 auxiliares de enfermería 56 eran los que preparaban, todos se lavaban las manos antes de comenzar la preparación de las drogas peligrosas, revisaban las prescripciones médicas y reunían el material y las drogas antes de iniciar la tarea, lo cual está acorde a todas las recomendaciones existentes para el manejo de estas drogas $(18,21)$. Solo un $8,9 \%$ usaban sobre túnicas específicas para la quimioterapia, en una sola de las ocho instituciones. Los otros auxiliares de enfermería que también preparaban estas drogas usaban la sobre túnica que tenían disponible en la institución, como puede ser impermeable o de tela, no cumpliendo así con las recomendaciones de los estándares (14-22). El 100\% preparaban las drogas dentro de una cabina de seguridad biológica, siguiendo las recomendaciones de los estándares internacionales. En cuanto al uso de guantes de vinilo, tapabocas N95, gafas y zapatones se observó no cumplimiento de las recomendaciones de los estándares (18-21).

La bioseguridad esta entendida como un conjunto de normas y procedimientos considerados seguros y adecuados para mantener la salud de los trabajadores (14-21), el no cumplimiento de las normas y procedimientos pone en riesgo la salud de los mismos.

Los auxiliares de enfermería en las ocho instituciones de salud tienen un rol fundamental en el proceso de administración de drogas peligrosas y 
se observó que la totalidad se lavaban las manos previa a la administración de las drogas peligrosas. En cuanto al uso del equipo de protección personal se advirtió un cumplimiento parcial de éste por parte de los auxiliares de enfermería, no acorde a las recomendaciones internacionales $(14,18-22)$. Lo mismo fue notado en las actividades referentes al proceso de los desechos de residuos de las drogas peligrosas.

El proceso de derrame de drogas peligrosas, en las ocho instituciones está protocolizado de acuerdo a las recomendaciones de los estándares internacionales para todo el equipo de salud, lo que incluye a las licenciadas en enfermería, auxiliares de enfermería, químicos farmacéuticos, auxiliares de farmacia y auxiliares de servicio, haciendo que se obtengan mejores resultados (14-22).

Al no adoptar las medidas de protección personal, el manipulador no solo se pone en riesgo a sí mismo sino al resto del equipo de salud y al medio ambiente, ya que el peligro de exposición se ve en las diferentes etapas. No existe $100 \%$ de seguridad en que tomando todas estas medidas se van a evitar posibles daños a futuro, pero sí se sabe que se pueden minimizar y en muchos casos prevenir. Por esa razón se hace tanto hincapié en llevar a cabo las recomendaciones de los estándares internacionales. Debido a que luego de muchos años se ha podido visualizar los daños que provocan estas drogas en los trabajadores de la salud, tanto en los que operan directamente, como en el resto. Referente a los químicos farmacéuticos se observó que el $100 \%$ realizaba las actividades del proceso de recepción y almacenamiento según lo pautado por los estándares internacionales $(14,22)$, cumpliendo de esta forma satisfactoriamente con las recomendaciones.

En el proceso de preparación de las drogas peligrosas fueron observados seis profesionales de un total de ocho. Todos se lavaban las manos, previo al procedimiento, revisaban la prescripción médica previamente, reunían el material y las drogas antes de comenzar la tarea, usaban doble par de guantes de vinilo, zapatones, tapaboca N95, sobre túnica impermeable y preparaban las drogas dentro de la cabina de seguridad biológica, cumpliendo con todas las recomendaciones internacionales $(14,18-21,24,27,28,34)$.

Los estándares internacionales recomiendan que en el proceso de preparación de las drogas peligrosas los responsables deben ser las licenciadas en enfermería y los químicos farmacéuticos (41). Los hallazgos de este estudio demuestran que en cuanto al cumplimiento de las normas internacionales los químicos farmacéuticos son los profesionales que más las respetan. En Uruguay existe una normativa (42) donde se indica que los químicos farmacéuticos deben estar a cargo de la Dirección Técnica del área de reconstitución de las drogas peligrosas, eso hace que en las instituciones que ya implementaron esto, el químico farmacéutico sea contratado exclusivamente para esa actividad y tengan la formación adecuada.

En cuanto a los auxiliares de farmacia solo una de las instituciones cuenta con dos de estos profesionales. Se observó que en todos los procesos del manejo de las drogas peligrosas cumplían de $50 \%$ a $100 \%$ con las normas estipuladas para cada proceso.

En relación a los auxiliares de servicio en el proceso de desecho de residuos de drogas peligrosas, se observó que el $100 \%$ retiraban las bolsas de los residuos y usaban guantes de limpieza, según lo estipulado y acorde a los estándares internacionales y a las normativas de las Instituciones de Salud del país que se rigen por el Ministerio de Salud Pública de Uruguay. En cuanto al uso de sobre túnica impermeable y de tapaboca triple filtro, el cumplimiento total no fue el sugerido por las recomendaciones de los estándares internacionales. El 100\% de ellos almacenaba los residuos adecuadamente y los identificaba según las disposiciones institucionales y nacionales, que están vinculadas a las internacionales (18-21).

En el proceso de derrame de drogas peligrosas los auxiliares de servicio no cumplen con los pro- 
tocolos de trabajo para este proceso.

La percepción que tiene el personal de salud sobre los riesgos y dificultades en el manejo de las drogas peligrosas, son variadas debido a la falta de marco regulatorio en el país.

Las dificultades en el manejo de estas drogas están relacionadas a la falta de recursos humanos, en cantidad y preparación, ya que no se cuenta con personal capacitado adecuadamente dificultando el manejo correcto de las drogas y consecuentemente exponiendo al resto del equipo y al medio ambiente a contaminación y por ende a riesgos. Un estudio americano que tuvo como objetivo demostrar el nivel de seguridad de las enfermeras que manejan drogas peligrosas, evidenció que cuanto mayor la formación académica y experiencia laboral en el área, mejores las medidas de bioseguridad que se adoptan. La enfermera que cuenta con formación académica y más años de experiencia en la especialidad se desarrolla en su labor tomando todas las precauciones pertinentes, para poder protegerse, proteger al resto del equipo y al medio ambiente, concluyendo ser fundamental el conocimiento que brinda la formación y la experiencia (43). Otro estudio europeo que se refiere al conocimiento, actitudes y creencias de las enfermeras sobre el manejo de las drogas peligrosas, mostró la importancia de la capacitación para desempeñarse en el área y saber tomar las medidas adecuadas de protección (44).

En el proceso de preparación y administración de las drogas, los hallazgos del presente estudio demostraron que el personal involucrado no cumple con las recomendaciones de los estándares internacionales en cuanto al equipo de protección personal. Los relatos de los participantes concluyen que la falta de conocimiento por parte del personal de enfermería se debe a que no hay enseñanza formal, el personal que ya está en el área es el que capacita al que ingresa a trabajar en la especialidad. Esto hace que todos trabajen de modo diferente porque no hay protocolos que regulen la formación, lo cual es fundamental para poder cumplir con las recomendaciones internacionales. En el análisis de los discursos, también se verificó la falta de recursos materiales siendo muchos de ellos no recomendados por los estándares internacionales, haciendo que la protección no cumpla su objetivo. En la fase de observación se pudo identificar que una sola institución contaba con túnica para quimioterapia y que en las otras restantes tenían impermeable descartable o de tela, lo que llevaba al personal usar la que había disponible. Los guantes de vinilo y tapabocas N95 tampoco estaban disponibles en todas las instituciones. La evidencia demuestra que preparar las drogas peligrosas en un área accesible con los implementos necesarios para mantener las drogas en condiciones, es fundamental y de importancia para minimizar los riesgos a los que se expone el personal de salud que las manipula (43).

Con los relatos de los participantes se pude asegurar que las dificultades en el manejo de las drogas peligrosas también se debían a problemas de infraestructura. Todas las instituciones cuentan con cabina de flujo laminar, pero estas no están colocadas en áreas adecuadas, donde haya poco tráfico; las condiciones del lugar no siempre son las recomendadas y no se cuenta con termómetro, alarma en el total de los refrigeradores, lo que no asegura un buen acondicionamiento de ellas. Según el Manual de recomendaciones para la manipulación de agentes citotóxicos - OSHA (18), el área de preparación de citostáticos debe estar ubicada en una zona restringida, de poco acceso, solo personal autorizado. Debe estar dividida en dos zonas, un área semilimpia y un área limpia que es donde se encuentra la cabina. Solo una de las instituciones contaba con estas características. Al no tener en el país políticas de salud relacionadas a esta especialidad se hace difícil que en todas las instituciones se lleven a cabo las recomendaciones de los estándares internacionales (18-21). Un estudio chileno que evalúo el riesgo de exposición ocupacional a citostáticos en una muestra de instalaciones destinadas a preparación de es- 
tas drogas, pertenecientes a la Red Nacional de Prestadores autorizados de Chile, reveló una gran variedad de situaciones en cuanto a la infraestructura para el manejo de las mismas, demostrando que solo un $7 \%$ del total de instalaciones evaluadas presentaban un nivel de control aceptable y cercano al óptimo esperado (45).

Los relatos revelan, las debilidades en el conocimiento del personal que trabaja en estas áreas, generan dificultades en los procedimientos; incide también la ausencia de protocolos, la falta de apoyo institucional y la ausencia de un marco regulatorio a nivel nacional. En Uruguay no existe un marco regulatorio, ni legislación para el manejo de las drogas peligrosas, lo que dificulta aún más la situación, ya que cada institución trabaja según su criterio y conocimiento, pues no son regidas por ningún organismo.

En relación a la percepción de los riesgos, el personal los reconoce y tiene conciencia de ellos, pero los atenúan ya que no se ven la mayoría de las veces a corto plazo minimizando la importancia que requieren. No estar capacitados y no contar con protocolos, perciben los riesgos en forma mínima o no los perciben. Sin embargo, reconocen que la capacitación, el conocimiento y el contar con protocolos de trabajo, ayudaría a que todo el personal trabajara a más conciencia.

El estudio "La Importancia de la Educación Permanente en la Prevención de Riesgos Laborales para las Enfermeras que se ocupan de los Fármacos Antineoplásicos" hace hincapié en la importancia de que las instituciones tengan trabajadores capacitados para prestar asistencia de calidad y alcanzar los objetivos deseados. Hace referencia a la necesidad de educación continua y actualización técnico-científica con programas de educación continuos, revisiones constantes y planeamiento dinámico, participativo e interdisciplinario (46).

En cuanto a la falta de las medidas de seguridad en el manejo de las drogas peligrosas, los relatos del personal de salud dejan ver que existe falta de medidas por parte de las instituciones, ya que no le brindan al personal todo lo necesario para trabajar adecuadamente y contar con todos los recursos necesarios para su protección. Por otra parte, se pudo verificar que en algunos casos sí se cuenta con los recursos, pero el personal no los usa adecuadamente por desconocimiento. En otros casos las instituciones no los proporcionan porque el personal no los solicita al desconocer lo que es útil e imprescindible para trabajar adecuadamente en un ambiente seguro.

Un estudio sobre los riesgos a que están expuestos los trabajadores de enfermería en la manipulación de quimioterápicos antineoplásicos, demostró que la mayoría de las veces los trabajadores consideran que la manipulación de estas drogas ofrece riesgos para la salud, pero que todavía no son capaces de identificar los riesgos claramente (47). Otro estudio brasileño cuyo objetivo fue identificar la percepción de enfermeros sobre bioseguridad en ambiente de cuidado quimioterápico, corrobora los resultados en cuanto a la necesidad de una legislación que proporcione un contexto seguro en el manejo de las drogas peligrosas, además de concluir que los profesionales perciben los riesgos a que están expuestos, pero no siempre adhieren a las medidas de protección (48).

Los logros obtenidos en el manejo de las drogas peligrosas se deben a la propia formación del personal y sus esfuerzos, a través del tiempo, pero en algunos relatos se constata que el haber podido capacitarse por sus propios medios ayudó a conseguir mejoras en sus lugares de trabajo, en cuanto a infraestructura, materiales y reconocimiento de su labor.

Es necesaria la concientización de los profesionales sobre medidas de seguridad en la administración de las drogas peligrosas y de esta forma, garantizar la calidad y seguridad brindada a los pacientes. La técnica de observación utilizada para la recolección de los datos, hace posible la obtención de los datos exactamente como ocurren y la observación de conductas no consideradas importantes por los participantes observados, la condición de 
ser observado puede de alguna manera alterar comportamientos; la escasa evidencia con enfoque en el tema propuesto, dificultó la confrontación de los resultados con la literatura.

\section{CONCLUSIONES}

De acuerdo con los objetivos planteados en este estudio se concluye que no hay cumplimiento de las recomendaciones de los estándares internacionales. Esto se debe a la falta de políticas públicas, al no contar en el país con un marco regulatorio que rija a todas las instituciones de salud. En las ocho instituciones de salud (públicas y privadas) el personal que recibe las drogas no es el mismo. Las drogas son recibidas y almacenadas tanto por licenciadas en enfermería, auxiliares de enfermería, químicos farmacéuticos y/o auxiliares de farmacia. No se cuenta con protocolos de trabajo referente al tema en ninguna institución, que determine específicamente quién debe realizar esta actividad, por ende, se realiza de acuerdo a la disponibilidad del personal existente en el momento de recepcionar y almacenar las drogas.

La preparación de las drogas está a cargo de las licenciadas en enfermería, químicos farmacéuticos, auxiliares de enfermería y/o auxiliares de farmacia, según las políticas institucionales, pero no por normativa del Ministerio de Salud Pública. Las recomendaciones internacionales incluyen a las licenciadas en enfermería y a los químicos farmacéuticos en el proceso de preparación de las drogas, por lo tanto, en este proceso tampoco se cumplen las normativas.

En la administración de las drogas sí se cumplen dichas normativas, pues en las ocho instituciones esta tarea está a cargo del personal de enfermería, sean licenciadas y/o auxiliares de enfermería. En el proceso de desecho de las drogas peligrosas, pautado por el Ministerio de Salud Pública, hay unificación de criterios en las ocho instituciones, estando acorde también a las recomendaciones de los estándares internacionales. Frente a un derrame de dichas drogas se observó que las ocho instituciones cuentan con protocolos de actuación, el $81,25 \%$ de las licenciadas en enfermería lo cumplen.

En cuanto a las auxiliares de enfermería en el proceso de derrame de drogas peligrosas se observó una oscilación que va desde el $26,3 \%$ al $94,7 \%$ que corresponde al registro de lo realizado y colocar los desechos en doble bolsa roja, respectivamente. El resto de las etapas de este proceso son cumplidas por más del $80 \%$ de los auxiliares de enfermería.

Con relación al segundo objetivo planteado de conocer la percepción de riesgos y dificultades del equipo de salud en el manejo de las drogas peligrosas, por medio de los relatos de los participantes se identificaron dificultades en recursos humanos, materiales e infraestructura, como también falta de conocimiento, capacitación, ausencia de protocolos, falta de apoyo institucional y ausencia del marco regulatorio relacionado al manejo de las drogas peligrosas a nivel país.

En todos los discursos se visualizó que por la falta del marco regulatorio aparecen las dificultades. Como Uruguay no cuenta con políticas de salud relacionadas al manejo de las drogas peligrosas, el personal de salud no está capacitado adecuadamente, desconoce las medidas que se deben tomar para su manejo y se exponen a riesgos relacionados a la incorrecta manipulación de estas drogas, ya que no hay quien regule la formación en la especialidad. Esta falta de marco regulatorio a nivel nacional trae aparejado las dificultades en los recursos humanos, materiales y de infraestructura. Se destaca la necesidad e importancia de contar en Uruguay con políticas públicas relacionadas al manejo de las drogas peligrosas, en especial, los citostáticos. Poder contar con informaciones uniformes basados en la evidencia científica y la experiencia de los participantes, permitirá alcanzar los objetivos de prevención y promoción de la salud de todos los profesionales y técnicos involucrados en el manejo de dichas drogas.

Las evidencias permiten un diagnóstico claro de la 
situación de las instituciones de salud de Uruguay en el manejo de las drogas peligrosas, ya que las instituciones participantes son las más representativas debido al número de usuarios que atienden, tanto niños como adultos.

Queda clara la relevancia que tienen las políticas de salud, respecto a la creación de un marco regulatorio el cual posibilitaría un cambio en la situación actual y disminuiría los posibles riesgos a los que se expone el personal de salud.

Que comprenda guías, protocolos, resoluciones, normas y decretos; eso posibilitará contar con personal formado y capacitado adecuadamente, con el equipo de protección personal recomendado por los estándares internacionales, con cabinas de seguridad biológica que cuenten con el correcto mantenimiento y ubicada en un lugar adecuado, entre otras acciones relacionadas a los recursos humanos, materiales y de infraestructura. Tales acciones proporcionarán la minimización de los riesgos del equipo de salud, la satisfacción laboral, la seguridad de los usuarios y la calidad de la atención.

DECLARACIÓN DE CONFLICTOS DE INTERESES: La autora no reporta ningún conflicto de interés. El estudio se realizó con recursos propios.

\section{REFERENCIAS}

(1) Protocolo de vigilancia sanitária especifica. Agentes citostáticos: salud laboral. Madrid: Ministerio de Sanidad y Consumo, 2003. 92 p. Disponible en: https://www.mscbs.gob.es/ciudadanos/ saludAmbLaboral/docs/Agentescitostaticos.pdf [Consulta 20/02/2017].

(2) American Society of Health-System Pharmacists. ASHP guidelines on handling hazardous drugs.Am J Health-SystPharm2018;75:1996-2031.

(3) Falck K, Gröhn P, Sorsa M, Vainio H, Heinonen $E$, Holsti L. Mutagenicity in urine of nurses handling cytostatic drugs. Lancet 1979; 9(1):1250-1.

(4) McDevitt JJ, Lees PSJ, McDiarmid MA.

Exposure of hospital pharmacists and nurses to antineoplastic agents. J Occup Med 1993; 35(1):57-60.

(5) Connor TH, Anderson RW, Sessink PJM, Broadfield L, Power LA. Surface contamination with antineoplastics agents in six cancer treatment centers in Canada and the United States. Am J Health-System Pharm1999; 56(14):1427-1432. doi: 10.1093/ajhp/56.14.1427

(6) Burgaz S, Karahalil B, Bayrak P, Tackin L, Yavuzaslan F, Bokesoy I, et al. Urinary cyclophosphamide excretion and micronuclei frecuencies in peripheral lymphocytes and in exfoliated buccal epithelial cells of nurses handling antineoplastics. Mutat Res 1999; 439(1):97-104. doi: 10.1016/s1383-5718(98)00180-6

(7) Maluf SW, Erdtmann B. Follow-up study of the genetic damage in lymphocytes of pharmacists and nurses handling antineoplastic drugs evaluated by cytokinesis-block micronuclei analysis and single cell gel electrophoresis assay.

Mutat Res 2000; 471(1-2):21-7. doi: 10.1016/s1383-5718(00)00107-8 
(8) Undeğer U, Başaran N, Kars A, Güç D. Assessment of DNA damage in nurses handling antineoplastic drugs by the alkaline COMET assay. Mutat Res 1999; 439(2):277-85.

doi: 10.1016/s1383-5718(99)00002-9

(9) Hemminki K, Kyyronen P, Lindbohm ML.

Spontaneous abortions and malformations in the offspring of nurses exposed to anesthetic gases, cytostatic drugs and other potential hazards in hospitals, based on registered information of outcome. J Epidemiol Community Health 1985; 39(2):141-7. doi: 10.1136/jech.39.2.141

(10) Selevan SG, Lindbohm ML, Hornung RW, Hemminki K. A study of occupational exposure to antineoplastic drugs and fetal loss in nurses. N Engl J Med 1985; 313(19):1173-8. doi: 10.1056/NEJM198511073131901

(11) Shortdge LA, Lemasters GK, Valanis B, Hertzberg V. Menstrual cycles in nurses handling antineoplastics drugs.

Cancer Nurs 1995; 18(6):439-44.

(12) Richter P, Calamera JC, Morgenfeld MC. Effect of chlorambucil on espermatogenesis in the human with malignant lymphoma.

Cancer 1970; 25(5):1026-30. doi: 10.1002/1097-0142(197005)25:5<1026::aidcncr2820250506>3.0.co;2-c

(13) Sherins JJ, DeVita VT Jr. Effect of drug treatment for lymphoma on male reproductive capacity. Ann Intern Med 1973; 79(2):216-20.

doi: $10.7326 / 0003-4819-79-2-216$

(14) Polovich M. Safe Handling of Hazardous Drugs. OJIN 2004; 9(3). Available from: http://ojin. nursingworld.org/MainMenuCategories/ANAMarketplace/ANAPeriodicals/OJIN/TableofContents/Volume92004/No3Sept04/HazardousDrugs.html [Consulted 22/02/2017].

(15) Keat CH, Sooaid NS, Yun CY, Sriraman M. Improving safety-related knowledge, attitude and practices of nurses handling cytotoxic anticancer drug: pharmacists' experience in a general hospital, Malaysia. Asian Pac J Cancer Prev 2013; 14(1):69-73. doi: 10.7314/apjcp.2013.14.1.69

(16) Polovich M, Clark PC. Factors Influencing Oncology Nurses' Use of Hazardous Drug Safe-Handling Precautions. ONF 2012; 39(3): E299-E309.

(17) Buschini A, Villarini M, Feretti D, Mussi F, Dominici L, Zerbini I et al. Multicentre study for the evaluation of mutagenic /carcinogenic risk in nurses exposed to antineoplastic drugs: assessment of DNA damage.

Occup Environ Med 2013; 70(11):789-94.

doi: 10.1136/oemed-2013-101475

(18) The American Society of Hospital Pharmacists (ASHP). Technical assistance bulletin on handling cytotoxic and hazardous drugs.

Am J Hosp Pharm 1990; 47(5):1033-49.

(19) American Society of Health-System Pharmacists. ASHP guidelines on a standardized method for pharmaceutical care. Am J Health-Syst Pharm 1996; 53:1713-6. Available from: https://www. ashp.org/-/media/assets/policy-guidelines/docs/ guidelines/standardized-method-pharmaceutical-care.ashx [Consulted 19/05/2017].

(20) The National Institute for Occupational Safety and Health (NIOSH). Pocket Guide to Chemical Hazards. Available from: https://www.cdc.gov/ niosh/npg/ [Consulted 19/02/2017].

(21) The Institute for Applied Healthcare Sciences (IFAHS). Available from: http://www.ifahs.org/ [Consulted 19/02/2017].

(22) Polovich M, White J, Kelleher O. Chemotherapy and biotherapy guidelines and recommendations for practice 2nd. ed. Pittsburgh, PA: Oncology Nursing Society, 2005.

(23) Sotaniemi EA, Sutinen S, Arranto AJ, Sutinen S, Sotaniemi KA, Lehtola J, Pelkonen RO. Liver damage in nurses handling cytostatic agents. Acta Med Scand 1983; 214(3):181-9. doi: 10.1111/j.0954-6820.1983.tb08593.x 
(24) Berruyer M, Tanguay C, Caron NJ, Lefebvre M, Bussières JF. Multicenter study of environmental contamination with antineoplastic drugs in 36 Canadian hospitals: a 2013 follow-up study.

J Occup Environ Hyg 2015; 12(2):87-94.

doi: 10.1080/15459624.2014.949725

(25) López MA; Martínez JD. Sistema de gestión de la prevención en el manejo de fármacos citostáticos. Metas Enferm 2006; 9(1):50-54.

(26) Ladeira C, Viegas S, Pádua M, Gomes M, Carolino E, Gomes MC, et al. Assessment of Genotoxic Effects in Nurses Handling Cytostatic Drugs. J Toxicol Environ Health 2014; 77(14-16):879-87. doi: $10.1080 / 15287394.2014 .910158$

(27) Costa M. Educação em biossegurança: contribuições pedagógicas para a formação profissional em saúde.

Ciênc Saúde Coletiva 2010; 15(1):1741-50.

https://doi.org/10.1590/S1413-812 32010000700086

(28) Santos CC. Percepção dos profissionais de enfermagem de um serviço de quimioterapia sobre os riscos ocupacionais. Rio de Janeiro; 2004. 99 p. Tese Apresentada a Universidade do Estado do Rio de Janeiro. Faculdade de Enfermagem para obtenção do grau de Mestre.

(29) Teixeira P, Valle S. Biossegurança: uma abordagem multidisciplinar. 1a. Reimp. Rio de Janeiro: Fiocruz, 1998. 442 p.

(30) Valle AR, Moura ME Nunes BM, Figueiredo ML. Biosecurity in the view of nurses.

Rev Enferm UERJ 2012; 20(3):361-7.

(31) Brand Cl, Fontana RT. Biossegurança na perspectiva da equipe de enfermagem de Unidades de Tratamento Intensivo. Rev Bras Enferm 2014; 67(1):78-84. https://doi.org/10.5935/0034-7167.20140010

(32) Wall ML, Miranda FMD, Sarquis LMM, Labronici LM, Cruz EDM. As crenças dos trabaIhadores de saúde nos acidentes de trabalho com exposição a fluido biológico: pesquisa descritiva. OBJN [Internet] 2011 [citado 2016 nov 15 nov]; 10:1. Acessível em: http://www.objnursing.uff.br/index. php/nursing/article/view/j.1676-4285.2011.3206.1

(33) Galimany-Masclans J, Torres-Egea P, Sancho-Agredano R, Girbau-García M, Fabrellas N, Torrens-Garcia ML. Gestión de los residuos sanitarios en el ámbito hospitalario.

Rev Enferm 2015; 38(5):14-19.

(34) Senna MH, Pestana AL, Lanzoni GMM, Erdmann AL, Meirelles BHS. Seguridad del trabajador en la manipulación de antineoplásicos. Av Enferm 2013; XXXI(1):141-158.

(35) Aran D, Laca H. Sistema de salud de Uruguay. Salud Publica Mex 2011; 53(suppl 2):S265-S274.

(36) Onwuegbuzie AJ, Jiao QG, Bostick SL. Library anxiety: Theory, research, and applications. Vol. 1. Lanham, MD, EEUU: Scarecrow Press, 2004. 392 p.

(37) Minayo MCS. O desafio do conhecimento. Pesquisa qualitativa em saúde. 9a. Edição revista e aprimorada. São Paulo: Hucitec, 2006. 406 p.

(38) Strauss A, Corbin J. Bases de la Investigación Cualitativa, técnicas y procedimientos para desarrollar una teoría fundamentada. Universidad de Antioquia. Colombia : Lemoine Editores, 2002. 341 p.

(39) Rodriguez Yunta E. Comités de evaluación ética y científica para la investigación en seres humanos y las pautas CIOMS 2002.

Acta Bioethica 2004; 10(1):37-48.

(40) Uruguay. Ministerio de Salud Pública.

Decreto del Poder Ejecutivo N¹35/999. Decreto de residuos biológicos. Disponible en: http://www. eutm.fmed.edu.uy/LICENCIATURAS\%20MVD/ mvdlaboratclinico/2012/decreto\%20residuos $\% 20$ biologicos $\% 20$ y 20 otros $\% 20$ actualizado\%20decreto\%20MSP\%20\%20586\%202009.pdf

[Consulta 30/04/2017]. 
(41) ISOPP Standards of practice. Safe handling of cytotoxics. J Oncol Pharm Practice J OncolPharm Practice. [internet]. 2007 Enero, [cited 2017 jun 12]; 13 Supp: 1-81. Available from: http:// eds.a.ebscohost.com/eds/detail/detail?vid=11\&sid=fdd29fbd-7142-4feb-9413-932fad537ea5\%40sessionmgr4008\&hid $=4202 \&$ bdata $=J$ mxhbmc9ZXMmc2I0ZT1IZHMtbGI2ZQ\%3d\%3d\#AN=edselc.2-52.0-38449102733\&db=edselc

(42) Uruguay. Poder Legislativo. Ley 15703.

Se regula la distribución, comercialización y dispensación de los medicamentos, cosméticos y dispositivos terapéuticos de uso humano y se deroga la ley 14.746. (Publicada Diario Oficial, $n^{\circ} 21918,(16-4$ - 1985).

Disponible en: htttps://legislativo.parlamento.gub.uy/ temporales/leytemp57236.htm [Consulta 20/06/2017].

(43) Jeong K, Lee B, Kwon M, Jang J. Safety management status among nurses handling anticancer drugs: nurse awareness and performance following Safety Regulations. Asian Pac J Cancer Prev [internet].2015, [cited2017jun23];16(8):3203-3211. Available from: http://eds.a.ebscohost.com/ehost/ detail/detail?vid=4\&sid=c8c309e8-b083-4ce9-b73e$-55 \mathrm{bcdef} 206 \mathrm{c} 4 \% 40$ sessionmgr4010\&hid=4202\&bdata =Jmxhbmc9ZXMmc2I0ZT1laG9zdC1saX$\mathrm{ZI} \# A N=25921121 \& \mathrm{db}=\mathrm{cmedm}$

(44) Kyprianou M, Kapsou M, Raftopoulos V, Soteriades ES. Knowledge, attitudes and beliefs of Cypriot nurses on the handling of antineoplastic agents. European J Oncology Nursing [internet]. 2010, [cited 2017 jun 23]; 14 (4): 278-282.

Available from: http://www.ejoncologynursing.com/ article/S1462-3889(10)00035-9/fulltext

(45) Villaroel Cantillana E. Identificación, análisis y evaluación del riesgo de exposición ocupacional en servicios de preparación de citostáticos de la Red Nacional de Prestadores. Cienc Trab. [Internet]. 2014 Abr [citado 2017Ago 07]; 16(49):56-64.Disponible en: https://scielo.conicyt.cl/scielo.php?script=sci_arttext\&pid=S0718-24492014000100010\&Ing=es. http://dx.doi.org/10.4067/S0718-24492014000100010
(46) de Morais EN, Soares E, Lamas AR, da Costa LM. A importância da educação continuada na prevenção dos riscos ocupacionais para os enfermeiros que manuseiam quimioterápicos antineoplásicos. Rev Pesquisa: Cuidado e Fundamental. [internet]. 2011 Abril, [citado 2017 julio 23]; 3 (2): 1822 - 1826. Acessível em: http://seer.unirio. br/index.php/cuidadofundamental/article/view/795 (47) Rocha FLR, Marciale MHP, Robazzi ML. Perigos potenciais a que estão expostos os trabaIhadores de enfermagem na manipulação de quimioterápicos antineoplásicos: conhecê-los para prevení-los. Rev Latino-Am Enfermagem [Internet]. 2004 June[citado2017Ago 07]; 12(3):511-517.Acessível em: http://www.scielo.br/scielo.php?script=sci_ arttext\&pid=S0104-11692004000300009\&lng=en . http://dx.doi.org/10.1590/S0104-11692004000300009

(48) Dos Santos W, da Silva AP, Ricardo L. Percepção dos trabalhadores de enfermagem quanto a biosegurança no cuidadoquimioterápico. Rev Enferm UFSM 2014; 4(1):172-180. doi: $10.5902 / 217976928531$ 